\title{
The Effect of Nephrotomy on Renal Function and Morphology in Normal Cats
}

\author{
By \\ Michael King \\ Thesis submitted to the Faculty of the Virginia Polytechnic Institute and State University \\ in partial fulfillment of the requirements for the degree of \\ Master of Science \\ In \\ Biomedical and Veterinary Sciences
}

Approval Committee:

\author{
Chair: Don R. Waldron, DVM, DACVS, DABVP \\ Don L. Barber, DVM, MS, DACVR \\ Martha M. Larson, DVM, MS, DACVR \\ Geoffrey K. Saunders, DVM, MS, DACVP \\ Gregory C. Troy, DVM, MS, DACVIM
}

May 2006

Blacksburg, Virginia

Keywords: Urogenital Surgery, Feline, Scintigraphy, Ultrasonography, Urolithiasis.

Copyright 2006, Michael King 


\title{
The Effect of Nephrotomy on Renal Function and Morphology in Normal Cats
}

By

Michael King

\begin{abstract}
Objective:

To assess effects of bisection nephrotomy on renal function, size, and morphology in cats over a period of 12 weeks.
\end{abstract}

\section{Study Design:}

Controlled, randomized, blinded experiment.

\section{Sample Population:}

Ten adult female cats.

\section{Methods:}

Glomerular filtration rate (GFR), as determined by quantitative renal scintigraphy using ${ }^{99 m}$ Tc-DTPA, urinalysis, urine culture, and sonographic measurement of renal size were performed pre-operatively. A left or right nephrotomy (five randomly assigned cats in each group) was performed. Total and individual kidney GFRs were determined in each cat 2, 28 and 84 days post-operatively. Both kidneys were measured sonographically 28 and 86 days postoperatively and an ultrasound-guided biopsy of each kidney was obtained 86 days postoperatively. 


\section{Results:}

No significant differences in mean GFR and kidney size of the operated versus unoperated kidneys were observed at any time period. Individual GFR and renal size of all except one of the cats remained within normal limits. Two additional cats had evidence of transient ureteral obstruction in the immediate post-operative period. No significant histologic abnormalities were observed in any biopsy.

\section{Conclusions:}

Bisection nephrotomy in normal cats did not adversely affect renal function or morphology over the three month post-operative period.

\section{Clinical Relevance:}

Bisection nephrotomy can be safely performed in normal feline kidneys without causing a significant deleterious effect on renal function. Studies in animals with pre-existing renal insufficiency are needed to insure no adverse effects would occur in clinical cases where this surgical procedure is warranted.

\section{Keywords:}

Urogenital Surgery, Feline, Scintigraphy, Ultrasonography, Urolithiasis. 


\section{ACKNOWLEDGEMENTS}

The author wishes to recognize the Virginia Veterinary Medical Association Veterinary Memorial Fund for providing funding for this project, and Dr. Don Waldron and Dr. Nancy Zimmerman-Pope for their work in acquiring the grant.

The author would like to recognize Ryan Gorbutt, Stephanie Milburn and Holly Phelps for their technical support, Dan Ward for statistical analysis, as well as Drs. Richard Broadstone and Stephanie Berry for assistance with anesthesia.

The author wishes to thank all the members of the graduate committee for their continued assistance throughout this project, and for their support of the author's professional career. 


\section{TABLE OF CONTENTS}

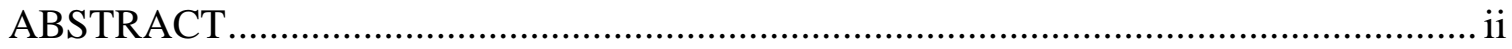

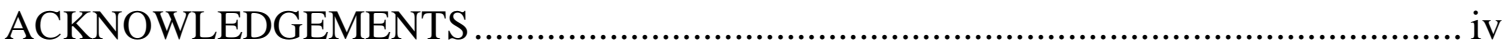

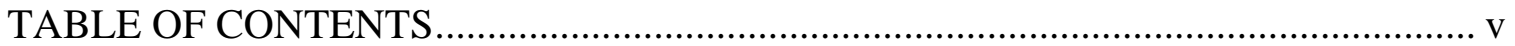

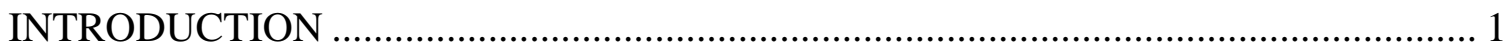

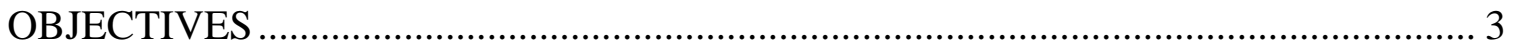

CHAPTER I: Literature Review ……………………............................................ 5

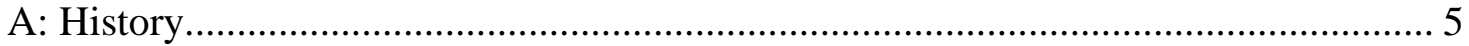

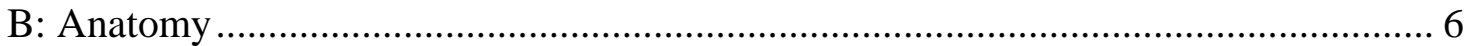

C: Methods of Determining Renal Function................................................................ 8

D: Methods of Assessing Renal Morphology ………….......................................... 13

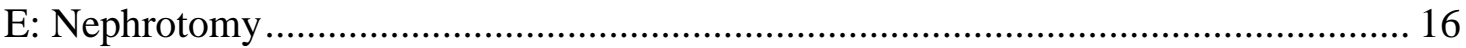

CHAPTER II: The Effect of Nephrotomy on Renal Function and Morphology in Normal

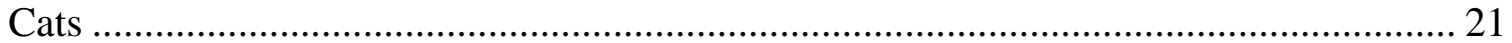

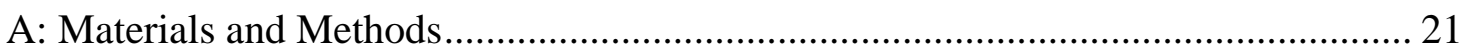

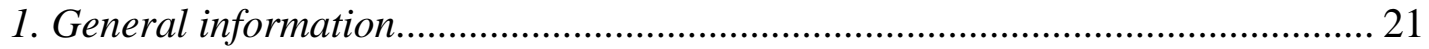

2. Pre-operative assessment............................................................................... 21

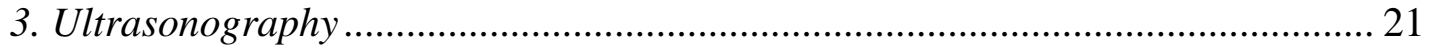

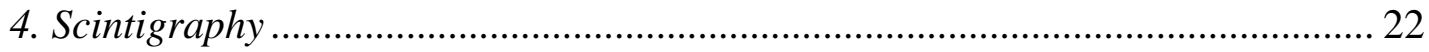

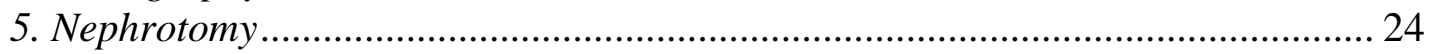

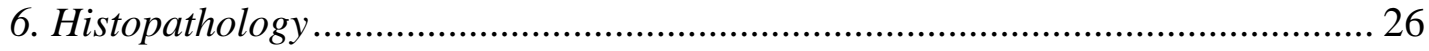

7. Statistical Analysis .................................................................................... 26

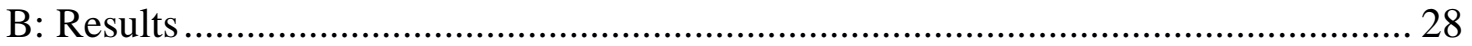

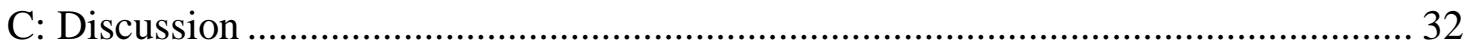

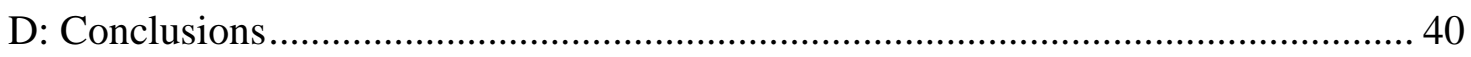

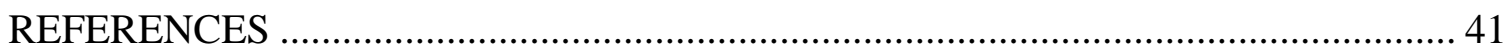

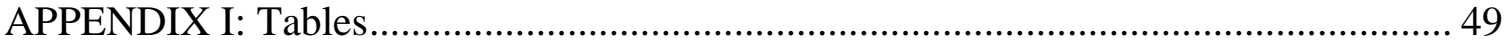

Table 1:Comparison of mean kidney size (least squares means) and standard error in all measured dimensions at all time periods, and associated p-values (standard error of the mean based on the pooled mean square for error)................................................. 49

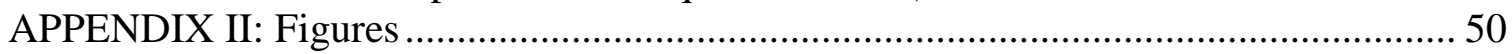

Figure 1: Comparison of mean single kidney GFR over time between operated and unoperated kidneys.

Figure 2: Comparison of mean longitudinal length between operated and unoperatedkidneys over time.

Figure 3: Comparison of mean longitudinal width between operated and un-operated kidneys over time.

Figure 4: Comparison of mean transverse width between operated and un-operated kidneys over time.

Figure 5: Comparison of mean transverse depth between operated and un-operated

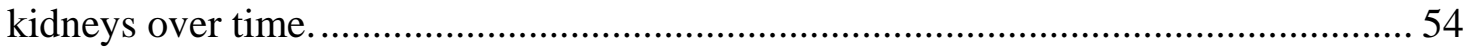
Figure 6: Comparison of mean longitudinal circumference between operated and unoperated kidneys over time.

Figure 7: Comparison of mean longitudinal area between operated and un-operated kidneys over time. 56 
Figure 8: Comparison of mean transverse circumference between operated and un-

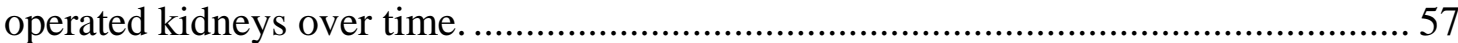

Figure 9: Comparison of mean transverse area between operated and un-operated

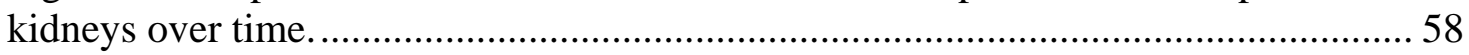

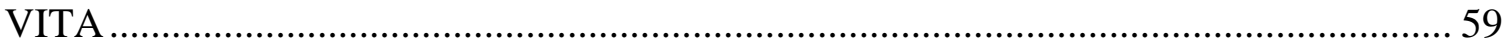




\section{INTRODUCTION}

Nephrotomy is most commonly performed in people and animals for excision of renal tumors, identification of causes of renal hematuria, and removal of renal calculi. Over the past two decades the composition and anatomic location of calculi within the urinary tract in cats has changed. ${ }^{1-3}$ Magnesium ammonium phosphate (struvite) stones constituted 78\% of all calculi from cats submitted for analysis to the Minnesota Urolith Center in 1981, but the prevalence of struvite stones decreased to $48 \%$ by 1996 and to $32 \%$ by 1999. The percentage of calcium oxalate (CaOx) calculi observed in cats increased from $1 \%$ to $55 \%$ of submissions to the Minnesota Urolith Center over the same time period. ${ }^{1-3}$ The most common type of nephrolith and ureterolith in cats is now calcium oxalate, followed by calcium phosphate. ${ }^{1,4-6}$ Calculi may be located anywhere within the urinary tract, but with increases in calcium oxalate urolithiasis there are fewer cases of urethral obstruction and an increased number of nephroliths and ureteroliths reported in cats. ${ }^{1,2,4,5}$

Treatment of $\mathrm{CaOx}$ calculi is difficult, as there are no current medical dissolution protocols available. ${ }^{7}$ Extracorporeal Shock-Wave Lithotripsy (ESWL) has been used successfully to treat struvite and $\mathrm{CaOx}$ nephroliths and ureteroliths in dogs, but results have been less rewarding in cats. ${ }^{8,9}$ Preliminary research suggests that ESWL doses must be lower in cats to avoid injury to the kidney, though more recent studies suggest this may not be the case. ${ }^{8,10,11}$ Calculi in cats are more difficult to disrupt using ESWL when compared to similar stones in dogs, leading to poor results when treating clinical cases. $^{8,11,12}$ For these reasons ESWL is not currently recommended as a treatment for feline nephrolithiasis, and surgical intervention by nephrotomy continues to be the only 
therapeutic option for removal of feline nephroliths when treatment is indicated. ${ }^{7,8,11}$ Until recently there have been no investigations relative to nephrotomy effects on kidney function in either normal cats or those with preexisting renal disease.

Early reports of nephrotomy in normal dogs showed a 20\% to 50\% reduction in Glomerular Filtration Rate (GFR) post-operatively, but two recent studies have shown bisection nephrotomy to have no effect on GFR in normal dogs. ${ }^{13-15}$ Cats with nephroliths often have compromised renal function, and it is unclear whether concurrent renal disease is a result of nephrolithiasis, whether renal disease predisposes to nephrolith formation, or whether these are independent events. ${ }^{4,5}$ Since concurrent renal disease is often present, nephrotomy has the potential to result in a further decline in kidney function by direct trauma to nephrons, disruption of vasculature, edema and fibrosis from the inflammatory response, or tissue ischemia from temporary occlusion of renal arterial blood flow. ${ }^{13-15}$ Because nephrotomy may cause additional damage to an already compromised kidney, removal in most cases is recommended only when calculi are suspected of causing direct obstruction, even though apparently asymptomatic nephroliths may pass into the ureter and cause clinical obstruction at a later date. ${ }^{16}$ Additionally, one group of investigators reported anecdotally a progressive decrease in size of feline kidneys subjected to nephrotomy. ${ }^{17}$ A recent report described a 10-20\% decrease in GFR of normal feline kidneys following nephrotomy when compared to unoperated control kidneys in the same animals. ${ }^{18}$ A significant decrease in GFR was not seen in the operated kidney until 52 weeks following the surgery, and the difference between operated and unoperated 
kidneys was not significant when the cats were assessed again at 78 weeks postoperatively.

Renal function in both dogs and cats is most often assessed clinically by measurement of blood urea nitrogen and creatinine levels. These biochemical tests are insensitive, as they require approximately $70 \%$ to $75 \%$ of nephrons to be non-functional before values

exceed normal ranges. ${ }^{19,20}$ Creatinine and inulin clearance rates are more sensitive biochemical tests but require 24 hour urine collections which are labor-intensive and require repeated catheterizations and blood sampling. ${ }^{19-21}$ More importantly, these tests measure total renal function and do not quantitate GFR of individual kidneys. ${ }^{19,21}$

Scintigraphic assessment of GFR using ${ }^{99 \mathrm{~m}}$ Technetium-diethylenetriaminepentaacetic acid $\left({ }^{99 \mathrm{~m}}\right.$ Tc-DTPA) correlates well with traditional methods of determining GFR in people and in dogs and cats, including creatinine and inulin clearance rates. ${ }^{19,21-24}$ It allows fast, accurate assessment of renal function and is regarded as the best noninvasive method for determining GFR in individual kidneys. ${ }^{19-22,24,25}$

\section{OBJECTIVES}

The primary objective of this study was to assess the effect of bisection nephrotomy on renal function in clinically normal cats by the use of quantitative scintigraphy. Additional objectives included assessing the effect of nephrotomy on renal size as determined by multi-dimensional sonographic measurement and any effect on renal morphology as assessed by renal needle biopsy. We hypothesized that bisection nephrotomy would not 
cause a significant decrease in renal function in the operated kidney and that morphologic changes in the operated kidney would be negligible. 


\section{CHAPTER I: Literature Review}

\section{A: History}

Surgery on the kidney may have had its beginnings several centuries B.C. with operations

performed by Hippocrates. ${ }^{26}$ The first authentic surgery performed on the kidney is reported to have occurred in 1501, when a number of calculi were removed from a renal abscess. During the late 1800s use of nephrotomy for removal of stones was reported on multiple occasions. These reports showed nephrotomy to be a feasible treatment option for diagnosis of a variety of human renal conditions and for removal of nephroliths. With the advent and use of radiography as a tool for diagnosing renal calculi, nephrotomy became more restricted to the role of removal of nephroliths. Disadvantages of nephrotomies were noted by several authors in the late $19^{\text {th }}$ and early $20^{\text {th }}$ centuries, with structural changes and a decrease in functional ability of the kidney post-nephrotomy reported. Post-operative infection and uro-cutaneous fistula formation were frequently encountered, as was a high incidence of post-operative hemorrhage. Infarction following incision into renal parenchyma was thought to be the cause for the higher incidence of complications seen in nephrotomy procedures when compared with pyelotomy. ${ }^{26}$ 


\section{B: Anatomy}

The feline kidneys are paired organs positioned dorsally within the abdomen in the retroperitoneal space. The right kidney lies opposite the first three lumbar vertebrae, with its cranial pole closely associated with the caudate process of the caudate lobe of the liver and the vena cava adjacent to its medial border. The left kidney is located slightly more caudal, lying adjacent to the second, third and fourth lumbar vertebrae, with the aorta positioned alongside its medial border. ${ }^{27,28}$ The kidney of the cat is bean-shaped and more spherical than those of the dog. In both species a hilus is present on the concave surface, through which pass vessels, lymphatics, and from which the ureter arises. ${ }^{29}$ The arterial supply to the kidney is via left and right renal arteries that originate directly from the aorta and enter the kidney at the hilus. ${ }^{28}$ The renal arteries branch into interlobar arteries which give rise to arcuate arteries. These divide further into interlobular arteries and finally terminate as glomerular capillaries. ${ }^{30,31}$ Similarly, venous drainage originates as peritubular capillaries emptying into interlobular veins. These progressively form arcuate, interlobar and finally left and right renal veins. The right renal vein empties directly into the vena cava while the left renal vein combines first with the gonadal vein..$^{27,29,31}$ Multiple renal veins are common in cats but rare in dogs. ${ }^{29}$ The surface of the feline kidney is smooth but grooved to accommodate prominent subcapsular veins which radiate towards the hilus and join the renal vein. ${ }^{28,29}$ The kidneys are surrounded by a thick and inelastic capsule which is attached to the underlying cortex, with numerous capillaries and lymphatics extending from it into the parenchyma. ${ }^{29}$

Feline kidneys are unipyramidal, with the parenchyma of the kidney divided into a lighter-colored cortex which surrounds a thicker and darker-colored medulla. ${ }^{29,30}$ The 
functional units of the kidney are nephrons. ${ }^{29-31}$ These structures begin with an expansion of epithelial tissue that is invaginated by a series of capillaries, known as a glomerulus, which is surrounded by an epithelial covering known as Bowman's capsule. Together these constitute a renal corpuscle and are distributed throughout the cortex, but they are not found within the renal medulla. ${ }^{29,30}$ The remaining part of the nephron consists of a long tubule which is separated into several sections. The proximal convoluted tubule is very tortuous, remaining close to the corpuscle from which it originates. It then forms a long hairpin loop known as the loop of Henle, which extends into the renal medulla. The ascending limb of this loop gives rise to the distal convoluted tubule, which again is located in the renal cortex near its corpuscle of origin..$^{29,30}$ Each nephron then drains into a collecting duct which serves many nephrons. These ducts run through the medulla before opening into larger papillary ducts which drain into the renal pelvis and then the ureter. $^{29-31}$

Urine formation begins with production of large amounts of ultrafiltrate plasma formed by the glomerulus, only a small portion of which is eventually excreted from the body as urine. Concentrations of substances within this ultrafiltrate are initially the same as within plasma. ${ }^{31}$ As the filtrate passes through the tubular system of the nephron it is altered by resorption of water and solutes and secretion of other substances from peritubular capillaries into the tubules. ${ }^{29,31}$ The rate at which any substance in plasma is excreted in urine depends on the relative rates of filtration, secretion and resorption of that substance during its passage through the nephron. ${ }^{31}$ 


\section{C: Methods of Determining Renal Function}

The primary role of kidneys is to maintain constancy of volume and composition of extracellular fluid by filtration of plasma and formation of urine. ${ }^{32}$ Determination of Glomerular Filtration Rate (GFR) is the best measurement of the functional state of the kidneys. ${ }^{33}$

The most frequently used methods of assessing renal function are measurement of plasma concentrations of substances normally excreted in urine, with the most common being urea and creatinine. Though easy to measure, these values are insensitive in their estimation of GFR and do not become significantly elevated until approximately 70-75\% of renal function has been lost. ${ }^{32,34}$ Their serum levels can also be affected by non-renal factors, principally their rate of production. Changes in hepatic function, as well as

dietary factors, will affect urea levels, as will the patient’s hydration status. ${ }^{32,34}$ Creatinine is less affected by extra-renal factors, though its production rate is affected by muscle mass. Creatinine values are increased in athletic breeds and decreased in cachectic animals. ${ }^{32,35}$ Additionally, a significant portion of compounds measured as creatinine in normal assessment of serum or plasma are not creatinine at all, but rather are noncreatinine chromogens such as ketone bodies. These are filtered from plasma by nonrenal routes, are not present in urine, and do not accumulate in the blood during azotemia. $^{32,34,36}$

In order to better quantify renal function, the concept of renal clearance was developed. Monitoring urinary excretion of a substance that can be detected and quantified in plasma provides an estimation of how well kidneys are functioning. ${ }^{32}$ If a substance is freely filtered by the glomerulus, yet is not subject to any resorption or additional secretion by 
the tubular system, then its clearance rate is equivalent to GFR. ${ }^{32,34,37,38}$ Renal clearance is defined as:

\section{(Urine concentration of substance) $X$ (Urine volume produced per minute) (Plasma concentration of substance)}

As the units of concentration cancel out, a measurement of urine clearance is determined as a volume per unit time $(\mathrm{ml} / \mathrm{min})$ and is an accurate approximation of GFR. ${ }^{32,34}$ Substances most commonly measured by clearance techniques are inulin and creatinine (endogenous and exogenous). ${ }^{32,34}$

Inulin is generally regarded as the gold standard for determination of GFR by urinary excretion clearance techniques in people and animals, as it fulfills the requirements of a clearance marker. ${ }^{21,32,39-41}$ However, inulin clearance requires intravenous infusion of inulin, multiple blood samples and carefully timed urine collection. Inulin assay is also laborious and difficult. ${ }^{32,41,42}$ For these reasons inulin clearance is occasionally used in a research setting but is not suitable for clinical use.

Creatinine clearance is more widely used in veterinary practice to estimate GFR. Measurement of endogenous creatinine clearance has the favorable attributes of inulin and other filtration markers but relies on production of creatinine within the body that occurs at a constant rate. ${ }^{32,34}$ It still requires accurately timed urine collection, but only one blood sample is required, and creatinine concentration is easily measured. ${ }^{32}$ Measurement of exogenous creatinine clearance rates has similar advantages, though it 
requires either an intravenous infusion or a subcutaneous injection of creatinine during the procedure. ${ }^{32}$ In people creatinine clearance is not commonly utilized as an estimation of GFR due to potential inaccuracies. ${ }^{38,40,42,43}$ Tubular secretion of creatinine does occur in people, and apparently increases with worsening renal insufficiency. ${ }^{38,40,43}$ Though tubular creatinine secretion does occur in male dogs (but apparently not in female dogs or in cats), it is negligible and not sufficient to invalidate results. ${ }^{32,34}$ Commonly used techniques for measuring plasma creatinine are not specific and frequently overestimate the actual amount of creatinine present in the blood. ${ }^{32,34,40}$ Exogenous clearance tests are thought to minimize this error by diluting the proportion of chromogens measured in plasma with the addition of the exogenous creatinine. ${ }^{32}$ In practice creatinine clearance in people provides a relatively accurate estimation of GFR when renal function is normal due to cancellation of errors; the overestimation due to tubular secretion is offset by the underestimation due to falsely elevated plasma measurement. ${ }^{36,40,44}$ Ideally, a peroxidasecoupled enzymatic method should be used in animals for measuring creatinine levels, as this is not affected by non-creatinine chromogens and avoids this potential inaccuracy. ${ }^{32}$ A variation of urinary excretion methods for determining clearance is use of plasma clearance rates to estimate GFR. ${ }^{32,34,45}$ Once a filtration marker has been administered to the patient and has distributed appropriately throughout body tissues, the rate of disappearance from the plasma (plasma clearance rate) should approximate GFR. This assumes that clearance of the marker from plasma occurs only through renal excretion, and as there is usually a small amount of extra-renal clearance of most filtration markers, renal function is overestimated with plasma clearance techniques at low levels of GFR. ${ }^{32,34}$ Most clearance tests assume complete distribution of the marker in the body 
within 1-2 hours after administration. If distribution is incomplete or slowed, then error may result from the continued process of distribution contributing to the subsequent fall in plasma levels of the marker. ${ }^{41}$ Substances used include iodine-containing contrast radiographic markers, radiolabelled markers, sodium sulfanilate, phenolsulfonphthalein (PSP), and sodium para-aminohippurate. ${ }^{32,34,45}$

After injection of the marker, serial blood samples are taken and analyzed for plasma levels of the substance. A plasma decay curve can be determined, and GFR can be determined from the slope and area under the curve. ${ }^{32,41}$

Non-ionic, low-osmolar iodine contrast radiographic markers such as iohexol can be used as filtration markers. ${ }^{32}$ While iohexol is readily available, it is expensive and equipment required to assay it is not routinely available. ${ }^{32}$ Iohexol is relatively safe with a low risk of nephrotoxicity and avoids safety issues associated with radionuclide markers. ${ }^{32,46}$ Use of iohexol as a filtration marker has been investigated in animals and determined to provide a reliable estimate of GFR. ${ }^{45}$

Plasma clearance of a variety of radiolabelled markers has been shown to be an accurate estimation of GFR in both people and animals..$^{32,41,47}$ Calculation of clearance rates via a single administration of a radioactive substance and determination of plasma levels is possible with a gamma camera. ${ }^{32,41}$ Disadvantages of these techniques are largely related to the radioactivity. Radiation safety concerns and availability of a scintillation camera and adequate facilities for such procedures limit these methods to academic institutions and research facilities. ${ }^{32,41}$ The most common radionuclides used as filtration markers in dogs and cats include ${ }^{51} \mathrm{Cr}$-ethylenediaminetetraacetic acid $\left({ }^{51} \mathrm{Cr}-\mathrm{EDTA}\right),{ }^{99 \mathrm{~m}} \mathrm{Tc}-$ 
diethylenetriaminepentaacetic acid $\left({ }^{99 \mathrm{~m}}\right.$ Tc-DTPA), and ${ }^{131}$ I-iothalamate, all of which have shown good correlation with biochemical methods of determining GFR. ${ }^{32,41}$ Renal scintigraphy is an additional way to utilize radiolabelled markers to determine GFR. A gamma-emitting compound is injected into the patient, and its accumulation within the kidney is monitored using a scintillation camera. ${ }^{34}$ The amount of radioactivity detected within the kidneys immediately following injection can then be used to determine the proportion of the marker being filtered by the kidney over a period of time, and this is quantified as a filtration rate by empirically based formulae. ${ }^{21,48}$ Compounds tagged to ${ }^{99 \mathrm{~m}}$ Technetium are the most common radionuclides used for this purpose in people and animals with variations including ${ }^{99 \mathrm{~m}} \mathrm{Tc}-\mathrm{DTPA},{ }^{99 \mathrm{~m}} \mathrm{Tc}-$ mercaptoacetyltriglycerine $\left({ }^{99 \mathrm{~m}} \mathrm{Tc}-\mathrm{MAG}\right),{ }^{99 \mathrm{~m}} \mathrm{Tc}$-glucoheptonate $\left({ }^{99 \mathrm{~m}} \mathrm{Tc}-\mathrm{GH}\right)$, and ${ }^{99 \mathrm{~m}} \mathrm{Tc}-$ dimercaptosuccinic acid $\left({ }^{99 \mathrm{~m}}\right.$ Tc-DMSA). ${ }^{19,49-54}$ The technique using ${ }^{99 \mathrm{~m}}$ Tc-DTPA correlates well with inulin clearance rates in cats with both normal and abnormal renal function. ${ }^{21}$ However in dogs there is evidence to suggest that plasma clearance of ${ }^{99 \mathrm{~m}} \mathrm{Tc}$ DTPA correlates better with inulin clearance techniques than does determination of GFR through percentage kidney uptake. ${ }^{24}$ Such quantitative renal scintigraphy is a noninvasive, accurate, reproducible, and rapid procedure that does not require blood or urine collection for analysis. The radioactive half life of ${ }^{99 \mathrm{~m}}$ Technetium is 6 hours, so it presents minimal exposure to radiation for both the patient and the operators, though specific isolation and monitoring facilities for veterinary patients are required. ${ }^{21,48,55}$ Scintigraphic measurement of radionuclides also allows for determination of individual kidney GFR and its contribution to total renal function, in comparison to clearance techniques which only provide quantification of global renal GFR. ${ }^{25,34,48,55,56}$ 


\section{D: Methods of Assessing Renal Morphology}

Ultrasound is an excellent technique for assessing internal architecture of parenchymal organs such as the kidney, and given their superficial location in small animals it is a commonly employed diagnostic modality in investigation of urinary tract diseases. ${ }^{57}$ Practical information regarding kidney size can be obtained from ultrasound assessment with measurement of a kidney’s linear dimensions. Ultrasound is especially useful in young or thin patients where the lack of abdominal fat reduces organ contrast on survey radiographs. ${ }^{57}$ Assessment of kidney volume can be determined using the linear measurements by calculation based on the volume of an ellipse. Some modern machines are able to generate elliptical measurements from screen images. ${ }^{57}$ In a recent human study, sonographically determined renal length and volume were seen to be significantly correlated with GFR in elderly patients and were sufficiently reproducible for this to be a useful clinical tool. ${ }^{58}$ However, renal ultrasound in pigs showed a significant error in assessment of actual renal size using both kidney length and volume measurements. ${ }^{59}$ In dogs, ultrasound is clinically useful for determining kidney size, with measurement in multiple planes producing an estimated renal volume that correlates well to actual renal size ${ }^{60-63}$ Potential inaccuracies in ultrasonographic evaluation of feline kidneys include observer visual error, imprecise border definition due to minimal capsular echo, and ultrasonographic artifacts. ${ }^{64}$

On ultrasound the renal cortex is uniform and is hyperechoic compared to the spleen in the normal cat. The renal medulla is anechoic and divided into segments by echogenic fat, blood vessels, and diverticuli extending from the pelvis. ${ }^{57,65}$ In cats, an echogenic line 
running parallel to the cortico-medullary junction (medullary rim sign) may be an incidental finding due to the presence of crystalline material within tubules. ${ }^{57}$ Studies in people evaluating Magnetic Resonance Imaging (MRI) as a technique of assessing the kidney have shown it to be a more accurate and repeatable method than ultrasonographic assessment of renal size. ${ }^{66,67}$ MRI has also been investigated as a method for evaluating GFR using contrast agents and fast-pulse sequencing. ${ }^{67}$ While visual assessment of kidneys both grossly and by ultrasound examination gives some information about morphology of the organs, renal biopsy with histologic assessment is essential in determining pathogenesis of both localized and diffuse disease. ${ }^{68}$ Several techniques are commonly employed, including surgical biopsy via laparotomy, keyhole biopsy, percutaneous core biopsy, and percutaneous aspiration (percutaneous techniques are commonly performed in combination with ultrasoundguidance). ${ }^{68}$ While the first three techniques provide tissue samples appropriate for histologic analysis, fine needle aspiration only supplies a sample of cells without an appreciation for organization or surrounding architecture. ${ }^{68}$ The most common biopsy technique used clinically is ultrasound-guided percutaneous core biopsy, as it provides a reasonably accurate and safe method of obtaining a single or serial biopsies with minimal detrimental effects. ${ }^{68,69}$ Minimum recommended size of a renal biopsy for accurate histopathologic evaluation is variable but ranges between 5 and 10 glomeruli. ${ }^{68,70,71} \mathrm{~A}$ variety of biopsy needle gauges are available, with higher quality biopsies obtained in dogs and people using larger size instruments. ${ }^{71,72}$ Major complications such as hemorrhage or infection are rare with percutaneous biopsy techniques in both people and 
animals. Minor localized hemorrhage is seen frequently on ultrasound examination of the biopsy site following the procedure, but this is not usually appreciable clinically. ${ }^{68,71-73}$ 


\section{E: Nephrotomy}

Currently in both people and animals nephrotomy is performed most commonly for removal of renal calculi. ${ }^{74,75}$ Other indications include excision of tumors and investigation of renal hematuria. ${ }^{74,75}$

A variety of nephrotomy incisions have been proposed to allow sufficient visualization of lesions while minimizing trauma to the kidney parenchyma. ${ }^{26}$ These include a transverse incision, a V-shaped incision, and multiple smaller nephrotomies over each affected region. The most common approach for extensive nephrotomy remains a bisection nephrotomy with incision over the convex border of the kidney. ${ }^{14,26,76}$ This has been further refined in people with the recommendation of an intersegmental nephrotomy to limit any detrimental effects on renal function. ${ }^{14}$ In this procedure the incision follows the intersegmental plane between the terminal artery branches of posterior and anterior renal arteries so as to avoid transaction of interlobar arteries. ${ }^{14}$

Though there has traditionally been concern about detrimental effects nephrotomy has on renal function in the operated kidney, in people it is unclear if such a permanent decrease in GFR occurs.

Fiorentini et al., investigated the effect of bivalve nephrotomy on renal function in people treated for renal calculi and found no marked irreversible damage to renal function. ${ }^{77}$ They noted a marked reduction in total GFR one month following surgery, though this value usually returned to pre-operative levels when patients were reassessed over a longer time period. The authors concluded that bisection nephrotomy was not significantly detrimental to function of the operated kidney, however, since only total GFR was 
measured, it is possible this return to preoperative levels may have been in part due to a compensatory increase in function of the contralateral kidney. ${ }^{77}$

Fitzpatrick et al., compared the effect on renal function of four different techniques for obtaining intrarenal access in people; extended sinus approach, radial paravascular approach, intersegmental nephrotomy, and bisection nephrotomy. ${ }^{78}$ They detected significant loss of renal function with all techniques except the extended sinus approach and concluded this was the best method of gaining access to the renal pelvis for removal of large calculi. Unfortunately, the extended sinus approach was the only technique in which they did not occlude the arterial supply of the kidney during the procedure. In all other cases the renal artery serving the operated kidney was occluded for 30 minutes while the nephrotomy was performed, and this lengthy ischemic time may have caused a more deleterious effect on renal function than the surgery itself. ${ }^{78}$

Balbay et al. reported a study in 1997 examining the effect of nephrotomy on renal function and size in people treated for nephroliths. ${ }^{51}$ They found no significant change in renal function or size following nephrotomy, having followed the patients for 3 months post-operatively. Assessment of renal function was performed both with serum urea and creatinine levels and with quantitative scintigraphy using ${ }^{99 \mathrm{~m}}$ Tc-DMSA. The blood supply to the kidney was not occluded during the surgical procedure in these patients. ${ }^{51}$ As early as 1911 concerns were raised about damage to renal tissue due to placement of mattress sutures used to provide hemostasis and closure of a nephrotomy incision. ${ }^{26}$ This concern was raised again in 1962 as ischemic necrosis was seen associated with both simple mattress and Lembert suture patterns used in renal parenchyma. ${ }^{26}$ Reports by one group of investigators in 1926 showed minimal damage to renal tissue after closure of 
nephrotomy incisions with capsular sutures only or no sutures at all. ${ }^{26}$ Reports by Paramo et al. ${ }^{79}$ in 1967, and Raney et al..$^{80}$ in 1975 showed sutureless techniques of nephrotomy closure to be effective clinically, but they did not examine the effects of such procedures on renal function or compare them to other methods of closure.

As in people, earlier information on effects of nephrotomy on renal function in animals suggested that it caused a significant decrease in GFR of the operated kidney. ${ }^{13,76}$ In 1977 Gahring et al. published a study describing the effects of sutureless nephrotomy and nephrotomy closed with mattress sutures on renal function in normal dogs. ${ }^{13} \mathrm{~A}$ significant decrease in GFR was seen in both groups, though it was more pronounced in nephrotomies closed with mattress sutures. Arterial supply to the operated kidney was occluded during the procedure in these dogs, though it was not standardized and instead reported as an average of 10-15 minutes ischemia time. The nephrotomy was achieved with sharp dissection only, in contrast with later studies that recommended blunt dissection through the parenchyma to minimize trauma to smaller arterioles. ${ }^{76}$ Subjects in the Gahring study were anesthetized with methoxyflurane, and administration of intravenous fluids during the period of anesthesia was not described. Methoxyflurane has been known to cause damage to renal tissue in people, though it is unknown if this is the case in animals. ${ }^{13,81}$

Two recent studies in normal dogs found that bisection nephrotomy had no significant effect on renal function in the operated kidney. ${ }^{14,15}$ In both studies, renal function was determined using scintigraphic uptake of ${ }^{99 \mathrm{~m}}$ Tc-DTPA, arterial occlusion time was standardized (10 minutes Stone et al. and 15 minutes Zimmerman-Pope et al.), and after a 
sharp incision into the renal capsule parenchymal dissection was continued bluntly to the renal pelvis. $^{14,15}$

Until recently there have been no studies investigating effects of nephrotomy on renal function in cats, with most previous information being extrapolated from studies in people or dogs. ${ }^{82,83}$ In August 2005, Bolliger et al published a study examining the effects of feline nephrotomy and found a modest reduction in GFR in operated kidneys when compared to un-operated controls. ${ }^{18}$ This decrease in GFR was not shown to be statistically significant until one year following surgery, and six months later it was no longer demonstrable as a significant difference between operated and un-operated kidneys. An overall decrease in GFR was seen in all kidneys when comparing preoperative measurements with all other time periods, both operated and un-operated. The authors propose a variety of factors other than nephrotomy as being the potential cause of this decrease, including changes in age, diet and hydration status. As the most noticeable change in GFR was seen between the pre-operative measurement and the first postoperative measurement, and as the investigators used a different sedation protocol for data collection at these two time periods, it is possible the initial steep decline in renal function noted in all kidneys was related to a drug effect and not surgery. Many commonly used sedatives have been shown to affect renal function by either direct effects on autoregulation of kidney perfusion or secondary to their effects on systemic blood pressure. ${ }^{81}$ While acepromazine is not known to have a direct effect on GFR, it is known to cause systemic hypotension, and the addition of this drug to the sedation protocol used in data collection post-operatively in the Bolliger study may have adversely affected renal function in all kidneys. ${ }^{18,81}$ As in the canine studies described previously, 
this report evaluated renal function following nephrotomy in normal animals. ${ }^{18}$ There remain no studies in the veterinary literature examining effects of nephrotomy on renal function in animals with pre-existing renal compromise or nephrolithiasis. 


\section{CHAPTER II: The Effect of Nephrotomy on Renal Function and Morphology in Normal Cats}

\section{A: Materials and Methods}

1. General information

Ten 9-month-old, female, domestic-short-haired cats were studied. They were obtained from a colony of purpose-bred research cats, housed together but isolated from contact with other animals, and fed a commercially available feline maintenance diet ad libitum throughout the research period. All procedures and diagnostics were approved by the Institutional Animal Use and Care Committee prior to commencement of the study.

\section{Pre-operative assessment}

Physical examination, complete blood count (CBC), serum chemistry profile, FIV/FeLV serologic tests, urinalysis, and urine culture were performed on each cat to assess general health status prior to inclusion in the study. Cultures were performed on urine samples obtained by cystocentesis at 48 hours, 28 days, and 84 days post-operatively. A pooled fecal flotation sample was analyzed for evidence of enteric parasitism.

\section{Ultrasonography}

Ultrasonography was performed to assess renal size seven days prior to surgery and 28 and 86 days post-operatively (Table 1). Each cat was sedated with an intramuscular injection of ketamine hydrochloride (10mg/kg bodyweight) for the first two examinations. On day 86 post-operatively, each cat was sedated with a combination subcutaneous injection of medetomidine ( $0.02 \mathrm{mg} / \mathrm{kg}$ bodyweight), butorphanol ( $0.2 \mathrm{mg} / \mathrm{kg}$ bodyweight) and ketamine hydrochloride ( $2 \mathrm{mg} / \mathrm{kg}$ bodyweight). 
Following sedation each cat was placed in dorsal recumbency, and kidneys were identified by ultrasonography using a $14 \mathrm{MHz}$ linear array transducer (Sequoia ${ }^{\mathrm{TM}}$; Siemans Medical Systems). Left and right kidneys were assessed in each cat on each study day by the same operator who had no knowledge of which kidney had been operated (ML). Measurements were made of each kidney in centimeters at the level of the renal crest in longitudinal and transverse planes for the following: circumference, cross-sectional area, length and width. ${ }^{64}$ Each variable was measured twice in centimeters, and the mean of the two measurements was used for data analysis.

On day 86 post-operatively, following recording of kidney dimensions, ultrasoundguided cortical biopsies were obtained of both kidneys using a 16 gauge Tru-cut ${ }^{\mathrm{TM}}$ biopsy needle. ${ }^{84}$ Kidneys were scanned in a longitudinal plane and were immobilized by manual pressure. Biopsies were obtained from the caudoventral aspect of each renal cortex, with the needle entering the caudoventral cortex and exiting through the caudal cortex at the caudal pole. The biopsy path was chosen to avoid the nephrotomy incision site, if visible. One hundred and twenty milliliters of isotonic saline was administered subcutaneously to each animal immediately after the biopsy to enhance urine production. The abdomen was assessed post biopsy by ultrasound for evidence of excessive hemorrhage, and the cat was examined hourly for the following 6 hours prior to being returned to the colony. ${ }^{84}$

\section{Scintigraphy}

Renal scintigraphy was performed seven days prior to surgery, 48 hours post-operatively, and 28 and 84 days post-operatively. Total and individual kidney GFRs were calculated 
by a previously described method. ${ }^{21}$ The scintillation camera (Technicare Omega 500 ${ }^{\mathrm{TM}}$ : Diagnostic Services Inc., Middlesex, NJ) was equipped with a low-energy, all-purpose, parallel-hole collimator. Each cat was sedated with an intramuscular injection of ketamine hydrochloride (10mg/kg bodyweight), and an intravenous catheter was placed in a cephalic vein. A 4mCi source of ${ }^{99 \mathrm{~m}}$ Tc-DTPA (Blueridge Nuclear Pharmacy, Roanoke, VA) was placed 26 centimeters from the detector, and a pre-injection count was obtained. The cat was then given a further intravenous injection of ketamine hydrochloride (5mg/kg bodyweight) and positioned in left recumbency, with the detector placed horizontally and centered over the abdomen in contact with the dorsum. The $4 \mathrm{mCi}$ dose of ${ }^{99 \mathrm{~m}}$ Tc-DTPA was housed in a lead-shielded syringe and attached to extension tubing that had been primed with heparinized saline and connected to the cephalic catheter. The extension tubing was loaded with the ${ }^{99 \mathrm{~m}} \mathrm{Tc}$-DTPA which was administered as a rapid bolus using saline solution $(0.9 \% \mathrm{NaCl})$ flush. A series of 51 six-second images was acquired using a computer and image acquisition software (Gamma 600, Release 2.1.3; Strichman Medical Equipment Inc.). Once all images were obtained, the intravenous catheter, extension tubing, empty dose syringe and needle were used to obtain a post-injection count. Actual activity injected was calculated as the difference between pre- and post-injection activity. Cats were then housed in a facility approved for low-level radiation until levels of detectable radiation were below $2 \mathrm{mR} / \mathrm{h}$ over the skin surface at the urinary bladder.

Using the summed image of all 51 images, regions of interest (ROI) were drawn freehand around the kidneys. Regions of interest were also drawn on the same image cranio- 
lateral and caudal to each kidney to determine background activity levels. Data was not depth-corrected. ${ }^{21}$ The same radiologist (DB) drew the ROI in all cases to minimize variability that can occur in delineating ROI, especially between individuals ${ }^{85-87}$ From these images, renal scintigraphic uptake was determined during the 1- to 3-minute postinjection interval, and from this data both total and individual left and right kidney GFRs were calculated. This was achieved using a modified spreadsheet analysis (Microsoft Excel; G. Daniel, personal communication, 2001) and a previously described technique for calculating GFR that has been shown to correlate well with inulin clearance rate determination of renal function. ${ }^{21}$

\section{Nephrotomy}

All surgeries were performed by either a board-certified surgeon (DW) or surgery resident (MK). All cats had food withheld for 12 hours prior to surgery. Each cat was given a subcutaneous injection of morphine $(0.2 \mathrm{mg} / \mathrm{kg}$ bodyweight), midazolam ( $0.2 \mathrm{mg} / \mathrm{kg}$ bodyweight), and atropine $(0.04 \mathrm{mg} / \mathrm{kg}$ bodyweight). An intravenous catheter was placed in a cephalic or medial saphenous vein, and anesthesia was induced with an intravenous injection of thiopental (10mg/kg bodyweight to effect). Each animal was intubated, and anesthesia was maintained through inhalation of isoflurane and oxygen. A catheter was placed in either the lingual or dorsal pedal artery, and direct arterial blood pressure measurements were recorded throughout the procedure. Intravenous fluid (lactated ringers solution) was administered at $10 \mathrm{ml} / \mathrm{kg} /$ hour during surgery.

The specific kidney that was operated was chosen prior to surgery. Asymmetry of individual kidney GFR was present on each cat's pre-operative scintigraphy, and thus 
attempts were made to avoid any bias that might result from this variation. The 10 cats were paired based on a similar percentage of the total pre-operative GFR contributed by each kidney. The left kidney was operated in one of each of the pair of cats, and the right kidney was operated in the other of the pair, determined by a coin toss. All investigators except the surgeons were blinded as to whether the left or right kidney was operated in each cat. A ventral midline celiotomy was performed, and the kidney to be operated was isolated. The kidney length was measured over its convex surface with a sterile ruler, and the extent of the planned nephrotomy incision (2/3 of the total kidney length) was marked at each end of the renal capsule with electrocautery. ${ }^{76}$ The renal artery or its arborizations were isolated by blunt dissection with a mosquito hemostat, and a bulldog clamp was placed across the vessel, completely occluding renal arterial blood flow. The clamp was maintained in place for exactly 15 minutes in all cases before being released ${ }^{88} \mathrm{~A}$ bisection nephrotomy was performed between the electrocautery marks previously made on the renal capsule. Initial incision through the capsule and into the parenchyma was made with a \#15 scalpel blade, and the incision was extended through the parenchyma to the renal pelvis using the blunt end of the scalpel handle. ${ }^{76,82}$ Once the nephrotomy dissection had been completed, a $3.5 \mathrm{~F}$ urinary catheter was passed into the renal pelvis until it could be palpated within the proximal ureter to confirm sufficient exposure of the pelvis. ${ }^{75,82,83}$ The renal pelvis was then flushed with isotonic saline prior to closure of the nephrotomy. The two halves of the kidney were then held in apposition while the nephrotomy incision was closed with a simple continuous suture pattern placed in the renal capsule using 5-0 poliglecaprone $25{ }^{75,82}$ The bulldog clamp was removed from the renal artery, and the surface of the kidney was assessed for bleeding, with additional 
simple interrupted sutures placed in areas where there was active hemorrhage. An ovariohysterectomy was performed in all cats during the same procedure, and the abdomen closed routinely.

For the first 24 hours post-operatively intravenous fluids were continued (lactated ringers solution $60 \mathrm{ml} / \mathrm{kg} / 24$ hours), and subcutaneous injections of buprenorphine $(0.01 \mathrm{mg} / \mathrm{kg}$ bodyweight) were administered to provide analgesia. Cats were housed separately during recovery, after which they were returned to the colony.

\section{Histopathology}

Renal biopsies were obtained 86 days post-operatively. Tissue was fixed in $10 \%$ neutral buffered formalin, embedded in paraffin, sectioned at 4 microns and stained with hematoxylin and eosin. Samples were evaluated under light microscopy for evidence and degree of fibrosis or inflammation. A grading system was used to assess the degree of inflammation and fibrosis. Grades included 0 (normal), 1 (mild: <33\% of biopsy affected), 2 (moderate: $33-67 \%$ of biopsy affected), or 3 (severe: $>67 \%$ of the biopsy affected). All renal biopsies were assessed by one pathologist (GS).

\section{Statistical Analysis}

Data analysis was performed using SAS software (SAS version 9.12, Gary NC). Individual kidneys were considered as the treatment subject (either operated or unoperated) with variables of interest being single kidney GFR and individual kidney dimensions as determined ultrasonographically. Data were evaluated for normality and identification of potential outliers and summarized as mean +/- standard error. 
Significance was set at $p<0.05$. A repeated measures analysis of variance was performed looking for differences in renal function or dimensions, between operated and unoperated kidneys irrespective of time (kidney effect), of all kidneys (both operated and unoperated combined) over time (day effect), and between operated and unoperated kidneys over time (kidney x day effect). 


\section{B: Results}

All cats were healthy based on physical examination. No abnormalities were detected on CBC, urinalysis or serum biochemistry in any of the cats. All cats were FIV/FeLV negative. Urine cultures were negative for bacterial growth at all sampling times. The pooled fecal sample revealed Giardia, and all cats were subsequently treated with metronidazole PO (50mg/kg bodyweight) once daily for five days prior to the start of the study. Follow-up treatment fecal examinations were negative for Giardia.

For the purposes of this study normal total GFR was defined as $>2.5 \mathrm{ml} / \mathrm{min} / \mathrm{kg}$, and normal individual kidney GFR was defined as $>1.25 \mathrm{ml} / \mathrm{min} / \mathrm{kg} .^{48}$ Nine of the 10 cats had normal pre-operative GFRs based on scintigraphy. The remaining cat had a preoperative total GFR of $1.69 \mathrm{ml} / \mathrm{min} / \mathrm{kg}$. This cat was removed from the study and replaced with a healthy, female-spayed cat, which had a normal GFR.

General anesthesia was induced and maintained without complication in all cats. Closure of all nephrotomies was completed prior to removal of the bulldog clamp, but in a few cats minor hemorrhage was observed at the nephrotomy incision site following removal of the vascular clamp. More complete hemostasis was achieved with either additional capsular sutures or gentle direct pressure using a moistened gauze sponge. Hemorrhage appeared to occur in cases where either the suture pulled through the capsule in some areas or where there was incomplete apposition of the incised capsule once the nephrotomy was closed. In two cats, there was marked hemorrhage from the parenchyma at the time of incision, and in both cases it was found the bulldog clamp had been placed 
across only one of the arborizations of the renal artery rather than the entire vessel. Once the clamp was repositioned to completely occlude renal arterial supply, hemorrhage subsided.

In one cat (cat \#5), moderate parenchymal and sub-capsular hemorrhage was observed after nephrotomy closure and following removal of the bulldog clamp. Additional interrupted sutures were placed in the renal capsule, and with direct pressure and placement of omentum over the nephrotomy site, adequate hemostasis was obtained. This subject was not observed to lose a significant amount of blood during the procedure, but it did have a prolonged recovery from anesthesia.

\section{Ultrasound}

Significant differences in mean kidney size were not observed in any measured dimension between operated and un-operated kidneys over time following surgery. There was a significant difference in the mean transverse width of all kidneys (operated and unoperated) between pre-operative measurements and measurements taken at other time periods, consisting of an upward trend consistent with kidney growth (Table 1). Other measured dimensions showed a similar trend but without statistical significance. A significant difference was also seen between the mean transverse width of operated and un-operated kidneys across all time periods, with operated kidneys seen to be larger in this dimension. This was noted in pre-operative as well as post-operative measurements and was not shown to be associated with any treatment effects. Some variation in renal size was present between operated and un-operated kidneys over time, though changes 
were not statistically significant. While both kidneys increased in size over the course of the study, operated kidneys appeared to have less increase in size than did un-operated kidneys.

In the majority of cases (9/10 cats) morphologic abnormalities observed sonographically in the operated kidney were mild and consisted of an irregularity along the convex cortical surface of the kidney. In cat \#5 a marked enlargement of the operated kidney was present 28 days post-operatively due to a mass consistent with a hematoma that obscured visualization of over $80 \%$ of normal renal parenchyma. At 86 days post-operatively, this cat had a substantial decrease in size of the operated kidney compared to the un-operated kidney. All statistical analysis of renal function and size included cat \#5.

\section{Renal Function}

Significant differences were not found in mean renal GFR between operated and unoperated kidneys at any time period during the study. A significant increase in GFR was present in all kidneys, operated and un-operated, 48 hours post-operatively compared to other time periods (Figure 1). Total GFR remained $>2.5 \mathrm{ml} / \mathrm{min} / \mathrm{kg}$ in all cats at all time periods. Throughout the study, individual kidney GFR remained $>1.25 \mathrm{ml} / \mathrm{min} / \mathrm{kg}$ in all kidneys with the exception of cat \#5. In that particular case, the GFR of the operated kidney decreased from $1.77 \mathrm{ml} / \mathrm{min} / \mathrm{kg}$ prior to surgery to $0.83 \mathrm{ml} / \mathrm{min} / \mathrm{kg}$ by 48 hours post-operatively and remained at $0.82 \mathrm{ml} / \mathrm{min} / \mathrm{kg}$ and $0.87 \mathrm{ml} / \mathrm{min} / \mathrm{kg}$ at 4 and 12 weeks, respectively, post-operatively. 
In two cases (cat \#1 \& \#7), a renogram pattern consistent with mild obstruction was observed in the operated kidney (cat \#1 more pronounced than \#7) at the 48 hour postoperative scintigraphic assessment. In both cats, scintigraphy was repeated 7 days later, and the renogram appeared normal. In cat \#7, scintigraphy at 48 hours post-operatively also revealed an area of radionuclide accumulation adjacent to the kidney consistent with leakage of urine from the renal parenchyma. The cat appeared healthy, and this scintigraphic abnormality had resolved when the study was repeated 7 days later.

\section{Histopathology}

Biopsies taken from 7 cats were of sufficient size and good quality with minimal fragmentation of the specimens. Biopsies taken from 2 cats were considered to be less

than adequate in quality and size (less than 5 glomeruli per biopsy). ${ }^{70,89}$ Samples from the remaining cat also had less than 5 glomeruli per biopsy, however the size and quality of these particular specimens was considered to be adequate by the examining pathologist (GS). No overt signs of inflammation or fibrosis were seen in samples from 9 of the cats, with all biopsies considered to be grade 0 . The sample taken from the operated kidney of cat \#5 had increased numbers of neutrophils and lymphocytes in the cortex and some evidence of tubular regeneration. This sample was considered to be grade 1 . 


\section{C: Discussion}

Nephrotomy can affect renal function in any of the following ways: direct trauma to nephrons, transection or disruption of renal vasculature, ischemia from temporary occlusion of renal arterial blood flow, or edema and fibrosis from the inflammatory repair response. ${ }^{13-15}$ Previous investigators found a $20 \%$ to $50 \%$ decrease in GFR immediately following nephrotomy in normal dogs. This reduction was most pronounced at 3 weeks after surgery but improved over the ensuing 3 week period. ${ }^{13}$ This finding was subsequently extrapolated to cats. ${ }^{75,82,83}$ A recent study showed a significant decrease in GFR of normal feline kidneys following nephrotomy when compared to unoperated kidneys in the same cats. ${ }^{18}$ This difference was not seen until 52 weeks following surgery though and was no longer significant when the animals were assessed again 78 weeks after surgery. ${ }^{18}$ An initial decrease in GFR following nephrotomy during the first postoperative month has also been seen in some people. ${ }^{77}$ Patients that had an initial decrease in GFR started to reverse this trend after the first post-operative month, tending to return towards pre-operative values. Because of this observation, it has been recommended that animals suffering from bilateral nephroliths have staged nephrotomies, 4-6 weeks apart, so as to not induce acute renal failure in the patient. ${ }^{75,82,83}$ Our investigation found no statistically significant effect on GFR of the operated kidney following bisection nephrotomy over the 12 week period of the study. This finding is in agreement with, and substantiates the recent study by Bolliger et al. ${ }^{18}$ In an earlier study Gahring et al ${ }^{13}$ compared renal function in sutured versus sutureless closure of the nephrotomy in healthy dogs. In the dogs with sutureless closure, nephrotomies were apposed by digital compression only until hemostasis was achieved, while in the sutured group the 
nephrotomies were closed with placement of a simple continuous capsular suture and horizontal mattress sutures passed through the renal parenchyma placed perpendicular to the incision. While both groups had a decrease in renal function, this finding was more pronounced in the suture group. This was thought to be due to the added trauma to nephrons and constriction of blood vessels caused by placement of parenchymal sutures. ${ }^{13}$ In contrast, nephrotomies performed by Stone et al ${ }^{14}$ and Zimmerman-Pope et al ${ }^{15}$ were closed with a simple continuous suture pattern that apposed the capsule without parenchymal mattress sutures. These studies, which were also performed on healthy dogs, showed no significant adverse effect on GFR following either bisection or intersegmental nephrotomy.

Another difference between the canine nephrotomy studies is surgical technique. Gahring et $\mathrm{al}^{13}$ incised sharply through the renal capsule and parenchyma down to the level of the renal pelvis. Stone et $\mathrm{al}^{14}$ and Zimmerman-Pope et al ${ }^{15}$ sharply incised through the capsule but then continued dissection through the parenchyma bluntly which is thought to cause less trauma to nephrons and renal vasculature. ${ }^{14,76}$ In all of our subjects the incision was made sharply into the capsule but then continued bluntly through the parenchyma to the level of the renal pelvis. All nephrotomies were then closed with a simple continuous pattern in the capsule only. Bolliger et a ${ }^{18}$ employed a similar surgical technique to our study, using blunt dissection to the renal pelvis, and closing all nephrotomies with capsular suture only. 
The kidney's autoregulatory capabilities maintain GFR following administration of a variety of sedation protocols. ${ }^{90-92}$ Some drug combinations commonly used in veterinary medicine have been shown to increase GFR, thought to be due to constriction of efferent arterioles resulting in increased glomerular hydrostatic pressure. ${ }^{92}$ In cases of systemic hypotension resulting from sedative administration, GFR is usually sustained at normal levels by maintenance of renal blood flow..$^{90,91}$

Animals studied by Gahring et al ${ }^{13}$ were anesthetized with thiamylal sodium and maintained with methoxyflurane and oxygen. Methoxyflurane has cardio-depressant effects and has been associated with acute renal failure in people, though direct effects on feline and canine renal function are uncommon. ${ }^{81}$ We used thiopental to induce anesthesia and maintained surgical depth with inhaled isoflurane administered in $100 \%$ oxygen. While thiopental has no direct effect on feline renal function, it can cause a transient drop in blood pressure or decreased renal blood flow if a large bolus is administered. ${ }^{81}$ No residual changes in renal function have been reported associated with administration of isoflurane, and it has less of a cardio-depressant effect than halothane or methoxyflurane. ${ }^{81}$ Isoflurane does cause a predictable decrease in GFR during anesthesia which is thought to be due to a direct effect on the renal autoregulatory system. ${ }^{49}$ Bolliger et al ${ }^{18}$ used general anesthesia to restrain their subjects for blood collection and scintigraphy as well as during surgery. During their pre-operative scintigraphic measurements and blood collection the cats were anesthetized with isoflurane only, while for all subsequent studies acepromazine and butorphanol were administered as a premedicant. They hypothesize that this alteration in the anesthetic protocol may have 
been a cause for the significant decrease in total GFR seen postoperatively in all their cats, both operated and unoperated. In our study, ketamine was used to provide sedation for scintigraphic and ultrasonographic assessments. Ketamine is a dissociative agent that has no effect on renal autoregulation but does cause an overall increase in systemic blood pressure. ${ }^{81}$ We chose this agent as it provides a short period of predictable sedation, is not known to adversely affect renal function, and has been used previously in cats to provide sedation for scintigraphic assessment of the urinary system. ${ }^{81,93}$ The total ketamine dose of $15 \mathrm{mg} / \mathrm{kg}$ used in this study is higher than that used in previous studies ${ }^{93}$ to allow restraint for intravenous catheter placement and ultrasound assessment, and to minimize patient movement during scintigraphic studies. In one previous report a $15 \mathrm{mg} / \mathrm{kg}$ dose was hypothesized to have contributed to slightly decreased GFR compared to other time periods where a lower ketamine dose was administered. ${ }^{94}$ However, acepromazine was also administered in conjunction with the ketamine at that particular time period in that study, and this may have caused the decreased GFR seen due to acepromazine's known hypotensive properties.

Administration of intravenous fluid during anesthesia is recommended to maintain cardiac output and support renal function. ${ }^{81}$ It has also been recommended to continue fluid administration post-operatively in nephrotomy patients both to maintain urine production and to assist in flushing blood clots from within the urinary system. ${ }^{74,76,82,83}$ We provided intravenous crystalloid fluid at recommended rates (lactated ringers solution at $10 \mathrm{ml} / \mathrm{kg} /$ hour $^{81}$ ) during anesthesia and then continued fluid administration over the first 24 hours post-operatively at a daily maintenance rate of $60 \mathrm{ml} / \mathrm{kg} / 24$ hours. ${ }^{81}$ In the 
earlier study by Gahring et al ${ }^{13}$ there was no description of use of intra-operative or perioperative fluids in any of the subjects, nor was there any description of blood pressure monitoring during the surgical procedures. Lack of fluids, along with anesthetic agents used and any hemorrhage during surgery, may have resulted in hypovolemia and hypotension which adversely affected renal function.

There was a significant increase in GFR in our study 48 hours post-operatively in both operated and un-operated kidneys when compared with other time periods. This was also noted in dogs studied by Stone et $\mathrm{al}^{14}$ where a $176 \%$ increase in total GFR was seen three days post-operatively, but GFR returned to basal levels 4 days later. As GFR is affected by hydration status, it is possible that this increase in GFR seen by Stone et al resulted from mannitol given preoperatively and from fluid therapy provided both intra- and postoperatively. ${ }^{95}$ We hypothesize that the significant increase in GFR of all kidneys noted at 48 hours post-operatively in our study was due to the increased hydration status of the subjects following administration of intravenous fluids during, and immediately following, surgery.

In two cats, an obstructive pattern was observed in the operated kidney 48 hours postoperatively, though in both instances this had resolved within 7 days. It is possible that the obstructive pattern was due to inflammation of the kidney or proximal ureter caused by surgical manipulation or by presence of a blood clot within the renal pelvis. ${ }^{96}$ For radiation safety reasons ultrasound assessment of the kidney and ureter could not be performed on these animals immediately following the scintigraphy. There was no 
apparent adverse effect on function of the operated kidney in either cat, though calculated GFR determined by percentage uptake of ${ }^{99 \mathrm{~m}}$ TC-DTPA may have been falsely elevated by delayed clearance of the radiopharmaceutical in these cases. ${ }^{24}$ Obstruction and hydronephrosis following feline nephrotomy was reported by Bolliger et $\mathrm{al}^{18}$ in one cat and was noted at their initial post-operative assessment 3 weeks after surgery. Though the cat remained clinically normal, the hydronephrosis was seen to persist and progress over the following 12 months, and a cause was not determined.

The reason for radionuclide accumulation outside of the kidney parenchyma in the one cat with a marked obstructive pattern is unknown. All nephrotomy incisions were closed by suturing in our study. It is also described that sufficient closure of the nephrotomy can be obtained without placement of sutures, with only digital pressure of the bisected kidney tissue allowing a fibrin seal to form, or with use of cyanoacrylate adhesive..$^{13,74,97}$ From the success reported with the latter techniques it is reasonable to assume that careful apposition of the capsule itself is not necessary to prevent leakage of urine into the abdomen in most animals. We speculate that the presence of a temporary obstruction, along with the incompletely healed nephrotomy, resulted in leakage of urine into a localized region outside of the capsule that would not have occurred had urine been able to flow normally. Post-operative leakage of urine from a nephrotomy incision in a cat has been previously reported. ${ }^{16}$ Though obstruction of urinary flow was not specifically documented in that clinical case, it is reasonable that post-operative ureteral obstruction may have occurred as the cat had an ipsilateral ureterotomy performed concurrently. 
One cat (cat \#5) in our study showed a significant reduction in GFR of the operated kidney at all time periods following surgery, as well as a dramatic change in morphology of that kidney. Surgical and anesthetic procedures were no different in this cat from others in the study, and the cause of these adverse effects is unknown. The only known difference is that the capsular closure in this animal was less than ideal due to suture pullout, and there was moderate hemorrhage from the nephrotomy incision following removal of the bulldog clamp. Hemostasis of the incision was achieved with placement of several additional capsular sutures and with placement of omentum over the surface of the kidney. The cat had a prolonged recovery from anesthesia but appeared otherwise clinically normal in the post-operative period. Ultrasonographic enlargement of the kidney and disruption of normal parenchyma 28 days post-operatively was consistent with renal hematoma or abscess, though the cat continued to have a good appetite and appeared clinically normal throughout the remainder of the study. At 12 weeks postoperatively a marked decrease in size of the kidney was seen sonographically. We speculate increased hemorrhage observed at surgery and resultant hematoma formation occurred due to transection of a large interlobar vessel. We further suggest this hemorrhage and vascular disruption caused substantial parenchymal damage that led to the decrease in renal size seen 12 weeks following surgery.

Ultrasound provides a non-invasive highly reproducible method of measuring actual kidney size in dogs and cats, though it has sometimes underestimated actual renal size. ${ }^{74,97,98}$ Ultrasonography is commonly used to evaluate the parenchyma of canine and feline kidneys and is effective at differentiating a variety of morphological 
abnormalities. ${ }^{16}$ We used ultrasound on days $-7,28$, and 86 to assess for effects of nephrotomy on kidney size by recording kidney dimensions in both transverse and longitudinal planes. Despite anecdotal reports of decreased renal size following nephrotomy in the cat, our results showed no statistically significant change in kidney size over time associated with surgery. ${ }^{17}$ This is in agreement with and supports the findings of a recent similar study. ${ }^{18}$ There was a significant change in renal width as measured in the transverse plane over time in both operated and un-operated kidneys in our subjects and a general trend (though not statistically significant) of overall increased kidney size over time. We attributed both of these findings to expected kidney growth in these experimental subjects, as it was seen in both operated and un-operated kidneys. Though not of statistical significance, the operated kidney did appear to have a smaller increase in size over time compared with the un-operated side, presumably due to healing and fibrosis of the nephrotomy affecting normal renal growth. If more animals had been included in the investigation, or if they had been followed for a longer period of time, it is possible that a significant effect on kidney growth could have been identified in this study. Despite anecdotal reports of decreased renal size following nephrotomy in the cat, our results showed no statistically significant change in kidney size over time associated with surgery. ${ }^{17}$

In order to be clinically useful, kidney biopsies must contain sufficient glomeruli for the pathologist to interpret the presence of pathology. Although the minimum number of glomeruli required for diagnostic interpretation varies among authors, most recommend at least 5-10 intact glomeruli within each sample for the biopsy to have a reasonable 
degree of accuracy. ${ }^{99,100}$ Ultrasound-guided biopsies have been shown to have no effect on renal function in the dog, however this has not been demonstrated in the cat. ${ }^{69}$ Biopsies of the operated kidney in the cats studied showed no marked abnormalities.

\section{D: Conclusions}

We conclude that bisection nephrotomy did not cause significant adverse effects on renal function or morphology in normal cats over the 12 week period of our study. This is a similar finding to other reports in dogs ${ }^{14,15}$ and supports the findings of a recent study in cats. ${ }^{18}$ It is unknown whether a significant effect would have been seen if we had included more cats or if assessment had been continued past the initial 12 weeks postoperatively. The authors recommend careful hemostasis and closure of the renal capsule to minimize the likelihood of individual post-operative complications. This study did not examine effects of nephrotomy in cats with pre-existing compromised renal function. Further investigation is required to determine whether there is any effect on renal function or size in such cases. 


\section{REFERENCES}

1. Salisbury KS: Management of Nephroliths and Ureteroliths in Cats, in 11th American College of Veterinary Surgeons Veterinary Symposium, pp 178-181, 2001

2. Bartges JW: Feline Calcium Oxalate Urolithiasis: Evidence for Treatment, in 19th American College of Veterinary Internal Medicine Meeting, pp 790-791, 2001

3. Lulich JP, Osborne CA, Lehkcharoensuk C, et al: Feline Nephroureterolithiasis, in 19th American College of Veterinary Internal Medicine Meeting, pp 792-793, 2001

4. Carter W, Hawkins E, Morrison W: Feline Nephrolithiasis: Eight Cases (1984 Through 1989). J Am Anim Hosp Assoc 29:247-256, 1993

5. Kyles AE, Hardie EM, Wooden BG, et al: Clinical, clinicopathologic, radiographic, and ultrasonographic abnormalities in cats with ureteral calculi: 163 cases (1984-2002). J Am Vet Med Assoc 226:932-936, 2005

6. Ling GV, Ruby AL, Johnson DL, et al: Renal calculi in dogs and cats: prevalence, mineral type, breed, age, and gender interrelationships (1981-1993). J Vet Intern Med 12:11-21, 1998

7. Bartges JW, Kirk C, Lane IF: Update: Management of calcium oxalate uroliths in dogs and cats. Vet Clin North Am Small Anim Pract 34, vii:969-987, 2004

8. Adams LG, Senior DF: Electrohydraulic and extracorporeal shock-wave lithotripsy. Vet Clin North Am Small Anim Pract 29, xv:293-302, 1999

9. Block G, Adams LG, Widmer WR, et al: Use of extracorporeal shock wave lithotripsy for treatment of nephrolithiasis and ureterolithiasis in five dogs. J Am Vet Med Assoc 208:531-536, 1996

10. Gonzales A, Labato M, Solano M, et al: Evaluation of the Safety of Extracorporeal Shock-Wave Lithotripsy in Cats., in 20th American College of Veterinary Internal Medicine Meeting, Dallas, TX, p 810, 2002

11. Lane IF: Lithotripsy: an update on urologic applications in small animals. Vet Clin North Am Small Anim Pract 34, vii:1011-1025, 2004

12. Adams LG, Williams Jr. JC, McAteer JA, et al: In Vitro evaluation of canine and feline urolith fragility by shockwave lithotripsy (abstract). J Vet Intern Med 17:406, 2003

13. Gahring DR, Crowe DT, Jr., Powers TE, et al: Comparative renal function studies of nephrotomy closure with and without sutures in dogs. J Am Vet Med Assoc 171:537-541, 1977 
14. Stone EA, Robertson JL, Metcalf MR: The effect of nephrotomy on renal function and morphology in dogs. Vet Surg 31:391-397, 2002

15. Zimmerman-Pope N, Waldron DR, Barber DL, et al: Effect of fenoldopam on renal function after nephrotomy in normal dogs. Vet Surg 32:566-573, 2003

16. Kyles AE, Hardie EM, Wooden BG, et al: Management and outcome of cats with ureteral calculi: 153 cases (1984-2002). J Am Vet Med Assoc 226:937-944, 2005

17. Ross SJ, Osborne CA, Lulich JP, et al: Canine and feline nephrolithiasis. Epidemiology, detection, and management. Vet Clin North Am Small Anim Pract 29, xiiixiv:231-250, 1999

18. Bolliger C, Walshaw R, Kruger JM, et al: Evaluation of the effects of nephrotomy on renal function in clinically normal cats. Am J Vet Res 66:1400-1407, 2005

19. Gates GF: Glomerular filtration rate: estimation from fractional renal accumulation of 99mTc-DTPA (stannous). Am J Roentgenol 138:565-570, 1982

20. Grauer GF: Diagnostic Tests for the Urinary System, in Nelson RW, Couto CG (eds): Small Animal Internal Medicine (ed 3). St. Louis, Missouri, Mosby, 2003, pp 584-598

21. Uribe D, Krawiec DR, Twardock AR, et al: Quantitative renal scintigraphic determination of the glomerular filtration rate in cats with normal and abnormal kidney function, using 99mTc-diethylenetriaminepentaacetic acid. Am J Vet Res 53:1101-1107, 1992

22. Krawiec DR, Twardock AR, Badertscher RR, 2nd, et al: Use of 99mTc diethylenetriaminepentaacetic acid for assessment of renal function in dogs with suspected renal disease. J Am Vet Med Assoc 192:1077-1080, 1988

23. Kampa N, Wennstrom U, Lord P, et al: Effect of region of interest selection and uptake measurement on glomerular filtration rate measured by 99mTc-DTPA scintigraphy in dogs. Vet Radiol Ultrasound 43:383-391, 2002

24. Barthez PY, Hornof WJ, Cowgill LD, et al: Comparison between the scintigraphic uptake and plasma clearance of 99mTc-diethylenetriaminepentacetic acid (DTPA) for the evaluation of the glomerular filtration rate in dogs. Vet Radiol Ultrasound 39:470-474, 1998

25. Daniel GB, Mitchell SK, Mawby D, et al: Renal nuclear medicine: a review. Vet Radiol Ultrasound 40:572-587, 1999

26. Maddern JP: Surgery of the staghorn calculus. British Association of Urological Surgeons Prize Essay. Br J Urol 39:237-275, 1967 
27. Evans HE, deLahunta A: The Abdomen, Pelvis, and Pelvic Limb, in Miller's Guide to the Dissection of the Dog (ed 4). Philadelphia, Pennsylvania, W.B. Saunders, 1996, pp $172-249$

28. Dyce KM, Sack WO, Wensing CJG: The Abdomen of Carnivores, in Textbook of Veterinary Anatomy (ed 2). Philadelphia, Pennsylvania, W.B. Saunders, 1996, pp 417-434

29. Osborne CA, Fletcher TF: Applied anatomy of the urinary system with clinicopathologic correlation., in Osborne CA, Finco DR (eds): Canine and Feline Nephrology and Urology, Williams \& Wilkins, 1995, pp 3-28

30. Dyce KM, Sack WO, Wensing CJG: The Urogenital Apparatus, in Textbook of Veterinary Anatomy (ed 2). Philadelphia, Pennsylvania, W.B. Saunders, 1996, pp 169-208

31. Guyton AC, Hall JE: Urine Formation by the kidneys, in Textbook of Medical Physiology (ed 9th). Philadelphia, PA, W.B. Saunders, 1996, pp 315-347

32. Gleadhill A, Michell AR: Clinical measurement of renal function, in Bainbridge J, Elliot J (eds): manual of Canine and Feline Nephrology and Urology. Gloucestershire, UK, British Small Animal Veterinary Association, 1996, pp 107-116

33. Barratt TM, Chantler C, Lederman S, et al: Assessment of renal function. Am J Kidney Dis 7:347-349, 1986

34. Finco DR: Evaluation of renal function, in Osborne CA, Finco DR (eds): Canine and Feline Nephrology and Urology, Williams \& Wilkins, 1995, pp 216-229

35. Hoste EA, Damen J, Vanholder RC, et al: Assessment of renal function in recently admitted critically ill patients with normal serum creatinine. Nephrol Dial Transplant 20:747-753, 2005

36. Lindeman RD: Assessment of renal function in the old. Special considerations. Clin Lab Med 13:269-277, 1993

37. Risch L, Blumberg A, Huber AR: Assessment of renal function in renal transplant patients using cystatin C. A comparison to other renal function markers and estimates. Ren Fail 23:439-448, 2001

38. Luke DR, Halstenson CE, Opsahl JA, et al: Validity of creatinine clearance estimates in the assessment of renal function. Clin Pharmacol Ther 48:503-508, 1990

39. Van Lente F, Suit P: Assessment of renal function by serum creatinine and creatinine clearance: glomerular filtration rate estimated by four procedures. Clin Chem 35:23262330, 1989 
40. Flynn FV: Assessment of renal function: selected developments. Clin Biochem 23:4954, 1990

41. Heiene R, Moe L: Pharmacokinetic aspects of measurement of glomerular filtration rate in the dog: a review. J Vet Intern Med 12:401-414, 1998

42. Fettman MJ, Allen TA, Wilke WL, et al: Single-injection method for evaluation of renal function with $14 \mathrm{C}$-inulin and $3 \mathrm{H}$-tetraethylammonium bromide in dogs and cats. Am J Vet Res 46:482-485, 1985

43. Barbara PG, Elisabetta M, Massimo G, et al: Assessment of renal function in the failing graft: a difficult task. Transplantation 76:443-444, 2003

44. Hurley RM: Assessment of renal function in the young. Special considerations. Clin Lab Med 13:257-267, 1993

45. Brown SA, Finco DR, Boudinot FD, et al: Evaluation of a single injection method, using iohexol, for estimating glomerular filtration rate in cats and dogs. Am J Vet Res 57:105-110, 1996

46. Agodoa L, Eknoyan G, Ingelfinger J, et al: Assessment of structure and function in progressive renal disease. Kidney Int (Suppl) 63:S144-150, 1997

47. MacDougall DF: Assessment of renal function in the dog. Vet Rec 108:232-234, 1981

48. Twardock AR, Krawiec DR, Itkin RJ: Renal Imaging I: Functional Renal Scintigraphy, in Berry CR, Daniel GB (eds): Handbook of Veterinary Nuclear Medicine. Raleigh, NC, North Carolina State University, 1996, pp 122-130

49. Mitchell SK, Toal RL, Daniel GB, et al: Evaluation of renal hemodynamics in awake and isoflurane-anesthetized cats with pulsed-wave Doppler and quantitative renal scintigraphy. Vet Radiol Ultrasound 39:451-458, 1998

50. Walsh DM, Royal HD: Evaluation of a single injection of 99mTc-labeled diethylenetriaminepentaacetic acid for measuring glomerular filtration rate in horses. Am J Vet Res 53:776-780, 1992

51. Balbay MD, Varoglu E, Devrim H, et al: Quantitative evaluation of renal parenchymal mass with 99mtechnetium dimercapto-succinic acid scintigraphy after nephrolithotomy. J Urol 157:1226-1228, 1997

52. Wessells H, Deirmenjian J, McAninch JW: Preservation of renal function after reconstruction for trauma: quantitative assessment with radionuclide scintigraphy. J Urol 157:1583-1586, 1997 
53. Kawamura J, Itoh H, Okada Y, et al: Preoperative and postoperative cortical function of the kidney with staghorn calculi assessed by 99mtechnetium-dimercaptosuccinic acid renal scintigraphy. J Urol 130:430-433, 1983

54. Larsson I, Lindstedt E, White T: Quantitative assessment of individual renal function. A comparison between creatinine excretion and a radionuclide method. Br J Urol 56:109112, 1984

55. Twardock AR, Krawiec DR, Lamb CR: Kidney scintigraphy. Semin Vet Med Surg (Small Anim) 6:164-169, 1991

56. Choe W: Extrarenal uptake of Tc-99m-DTPA in a case of retroperitoneal abscess causing spurious data in renal function assessment. Ann Nucl Med 12:165-167, 1998

57. Dennis R: Diagnostic imaging of the urinary tract, in Bainbridge J, Elliot J (eds): Manual of Canine and Feline Nephrology and Urology. Gloucestershire, UK, British Small Animal Veterinary Association, 1996, pp 124-147

58. Van Den Noortgate N, Velghe A, Petrovic M, et al: The role of ultrasonography in the assessment of renal function in the elderly. J Nephrol 16:658-662, 2003

59. Ferrer FA, McKenna PH, Bauer MB, et al: Accuracy of renal ultrasound measurements for predicting actual kidney size. J Urol 157:2278-2281, 1997

60. Nyland TG, Kantrowitz BM, Fisher PE, et al: Ultrasonic determination of kidney volume in the dog. Vet Radiol Ultrasound 30:174-180, 1989

61. Nyland TG, Fisher PE, Gregory CR, et al: Ultrasonographic evaluation of renal size in dogs with acute allograft rejection. Vet Radiol Ultrasound 38:55-61, 1997

62. Barr F: Evaluation of ultrasound as a method of assessing renal size in the dog. J Small Anim Pract 31:174-179, 1990

63. Felkai C, Voros K, Vrabely T, et al: Ultrasonographic determination of renal volume in the dog. Vet Radiol Ultrasound 33:292-296, 1992

64. Walter PA, Feeney DA, Johnston GR, et al: Feline renal ultrasonography: quantitative analyses of imaged anatomy. Am J Vet Res 48:596-599, 1987

65. Nyland TG, Mattoon JS, Wisner ER: Ultrasonographyof the Urinary Tract and Adrenal Glands, in Veterinary Diagnostic Ultrasound. Philadelphia, PA, W.B. Saunders, 1995, pp 95-124

66. Bakker J, Olree M, Kaatee R, et al: In vitro measurement of kidney size: comparison of ultrasonography and MRI. Ultrasound Med Biol 24:683-688, 1998 
67. Knesplova L, Krestin GP: Magnetic resonance in the assessment of renal function. Eur Radiol 8:201-211, 1998

68. MacDougall DF, Lamb CR: Renal biopsy, in Bainbridge J, Elliot J (eds): Manual of Canine and Feline Nephrology and Urology. Gloucestershire, UK, British Small Animal Veterinary Association, 1996, pp 148-160

69. Groman RP, Bahr A, Berridge BR, et al: Effects of serial ultrasound-guided renal biopsies on kidneys of healthy adolescent dogs. Vet Radiol Ultrasound 45:62-69, 2004

70. Wise LA, Allen TA, Cartwright M: Comparison of renal biopsy techniques in dogs. J Am Vet Med Assoc 195:935-939, 1989

71. Rawlings CA, Diamond H, Howerth EW, et al: Diagnostic quality of percutaneous kidney biopsy specimens obtained with laparoscopy versus ultrasound guidance in dogs. J Am Vet Med Assoc 223:317-321, 2003

72. Song JH, Cronan JJ: Percutaneous biopsy in diffuse renal disease: comparison of 18and 14-gauge automated biopsy devices. J Vasc Interv Radiol 9:651-655, 1998

73. Bach D, Wirth C, Schott G, et al: Percutaneous renal biopsy: three years of experience with the biopty gun in 761 cases--a survey of results and complications. Int Urol Nephrol 31:15-22, 1999

74. Gourley IM: Symposium on surgical techniques in small animal practice. Nephrectomy and nephrolithotomy. Vet Clin North Am Small Anim Pract 5:401-413, 1975

75. Fossum TW: Surgery of the Kidney and Ureter, in Fossum TW (ed): Small Animal Surgery (ed 2). St. Louis, Missouri, Mosby, 2002, pp 549-571

76. Stone EA: Canine Nephrotomy. Compend Contin Educ Pract Vet 9:883-889, 1987

77. Fiorentini L, Minervini R, Palla R, et al: The effect of bivalve nephrotomy on renal function in patients with staghorn calculi. J Nucl Med Allied Sci 24:159-161, 1980

78. Fitzpatrick JM, Sleight MW, Braack A, et al: Intrarenal access: effects on renal function and morphology. Br J Urol 52:409-414, 1980

79. Paramo PG, D'Ocon MT, De la Pena A: Sutureless nephrotomy. J Urol 98:456-458, 1967

80. Raney AM, DeBenedictis TJ, Zimskind PD: Sutureless bivalve nephrotomy with compression hemostasis. Urology 6:339-342, 1975

81. Muir WW, Hubbell JAE, in Handbook of Veterinary Anesthesia (ed 3). St Louis, Missouri, Mosby, 2000, pp 164-181 
82. Kyles AE, Stone EA: Removal of Nephroliths, in Bojrab M (ed): Current Techniques in Small Animal Surgery (ed 4). Baltimore, MD, Lippincott Williams \& Wilkins, 1998, pp 431-434

83. Rawlings CA, Bjorling DE, Christie BA: Kidneys, in Slatter DH (ed): Textbook of Small Animal Surgery (ed 3). Philadelphia, PA, Saunders, 2003, pp 1606-1619

84. Nyland TG, Mattoon JS, Wisner ER: Ultrasound-Guided Biopsy, in Nyland TG, Mattoon JS (eds): Veterinary Diagnostic Ultrasound. Philadelphia, PA, Saunders, 1995, pp $30-42$

85. Samii VF, Kyles AE, Long CD, et al: Evaluation of interoperator variance in shunt fraction calculation after transcolonic scintigraphy for diagnosis of portosystemic shunts in dogs and cats. J Am Vet Med Assoc 218:1116-1119, 2001

86. Kampa N, Bostrom I, Lord P, et al: Day-to-day variability in glomerular filtration rate in normal dogs by scintigraphic technique. J Vet Med A Physiol Pathol Clin Med 50:37-41, 2003

87. Kampa N, Lord P, Maripuu E: Effect of observer variability on glomerular filtration rate measurement by renal scintigraphy in dogs. Veterinary Radiol Ultrasound 47:212-221, 2006

88. Selkurt EE: The changes in renal clearance after complete ischemia of the kidney. Am J Physiol 144:395-403, 1945

89. Solez K, Axelsen RA, Benediktsson H, et al: International standardization of criteria for the histologic diagnosis of renal allograft rejection: the Banff working classification of kidney transplant pathology. Kidney Int 44:411-422, 1993

90. Bostrom I, Nyman G, Kampa N, et al: Effects of acepromazine on renal function in anesthetized dogs. Am J Vet Res 64:590-598, 2003

91. Newell SM, Ko JC, Ginn PE, et al: Effects of three sedative protocols on glomerular filtration rate in clinically normal dogs. Am J Vet Res 58:446-450, 1997

92. Grimm JB, Grimm KA, Kneller SK, et al: The effect of a combination of medetomidine-butorphanol and medetomidine, butorphanol, atropine on glomerular filtration rate in dogs. Vet Radiol Ultrasound 42:458-462, 2001

93. Newell SM, Ellison GW, Graham JP, et al: Scintigraphic, sonographic, and histologic evaluation of renal autotransplantation in cats. Am J Vet Res 60:775-779, 1999

94. Drost WT, Henry GA, Meinkoth JH, et al: The effects of a unilateral ultrasound-guided renal biopsy on renal function in healthy sedated cats. Vet Radiol Ultrasound 41:57-62, 2000 
95. DiBartola SP: Renal Physiology, in DiBartola SP (ed): Fluid Therapy in Small Animal Practice (ed 2). Philadelphia, PA, Saunders, 2000, pp 26-41

96. McLoughlin MA: Surgical emergencies of the urinary tract. Vet Clin North Am Small Anim Pract 30:581-601, vi-vii, 2000

97. Weedon GR, Birchard S: The sutureless nephrotomy closure: a photographic essay. Vet Med Small Anim Clin 75:1365-1369, 1980

98. Gahring DR, Crowe DTF: Feline renal function studies of imaged anatomy. Am J Vet Res 48:596-599, 1977

99. Walter PA, Feeney DA, Allen TA, et al: Feline renal biopsy techniques in dogs. Am J Vet Res 48:596-599, 1987

100. Solez K, Axelsen RA, Leveille R: Renal ultrasonographic and computed tomographic appearance, volume, and function of cats with autosomal dominant polycystic kidney disease. Kidney Int 43:368-373, 2002 


\section{APPENDIX I: Tables}

\section{Table 1:Comparison of mean kidney size (least squares means) and standard error in all measured dimensions at all time periods, and associated p-values (standard error of the mean based on the pooled mean square for error).}

All measurements are reported in centimeters. Day = number of days pre- or postsurgery (day of surgery $=0$ ); $\mathrm{O}=$ Operated kidney; $\mathrm{N}=$ Not operated. LL = Longitudinal Length (cranial-caudal length); LW = Longitudinal Width (dorso-ventral measurement); TW = Transverse Width (dorso-ventral measurement); TD = Transverse Depth (mediallateral measurement); LC = Longitudinal Circumference; LA = Longitudinal Area; TC = Transverse Circumference; TA = Transverse Area. P-values listed include Kidney, Day, and Kidney by Day (K x D) effects for each measurement (significant effects in bold text).

\begin{tabular}{lccccccccc}
\hline Day & Kidney & LL & LW & TW & TD & LC & LA & TC & TA \\
\hline \hline-7 & $\mathrm{O}$ & 3.5847 & 1.9375 & 1.9970 & 2.2585 & 8.9235 & 5.5435 & 6.7115 & 3.5590 \\
-7 & $\mathrm{~N}$ & 3.5785 & 1.9042 & 1.8750 & 2.2845 & 8.9675 & 5.5555 & 6.5432 & 3.3495 \\
28 & $\mathrm{O}$ & 3.7120 & 1.9973 & 2.1115 & 2.2770 & 9.3630 & 6.0675 & 7.0057 & 3.9298 \\
28 & $\mathrm{~N}$ & 3.6462 & 1.9178 & 1.9675 & 2.2225 & 9.0748 & 5.6627 & 6.6395 & 3.4745 \\
86 & $\mathrm{O}$ & 3.6225 & 1.8825 & 2.0775 & 2.1430 & 9.0442 & 5.9720 & 6.6027 & 3.4555 \\
86 & $\mathrm{~N}$ & 3.7175 & 2.0410 & 2.1100 & 2.3030 & 9.3447 & 6.0523 & 6.9865 & 3.8590 \\
& $\mathrm{Std}$. & \pm & \pm & \pm & \pm & \pm & \pm & \pm & \pm \\
& Error & 0.08231 & 0.06466 & 0.06692 & 0.07305 & 0.2014 & 0.2281 & 0.1798 & 0.2051 \\
\hline P- & Effect & & & & & & & & \\
values & Kidney & 0.8967 & 0.7343 & $\mathbf{0 . 0 0 4 3}$ & 0.5249 & 0.8551 & 0.3822 & 0.6020 & 0.4095 \\
& Day & 0.3293 & 0.7326 & $\mathbf{0 . 0 3 1 4}$ & 0.7569 & 0.3063 & 0.0675 & 0.4999 & 0.4405 \\
& K x D & 0.5267 & 0.0992 & 0.2660 & 0.2606 & 0.3238 & 0.4165 & 0.1055 & 0.1097 \\
\hline
\end{tabular}




\section{APPENDIX II: Figures}

Figure 1: Comparison of mean single kidney GFR over time between operated and un-operated kidneys.

(Nephrotomy performed at Day $=0$ )

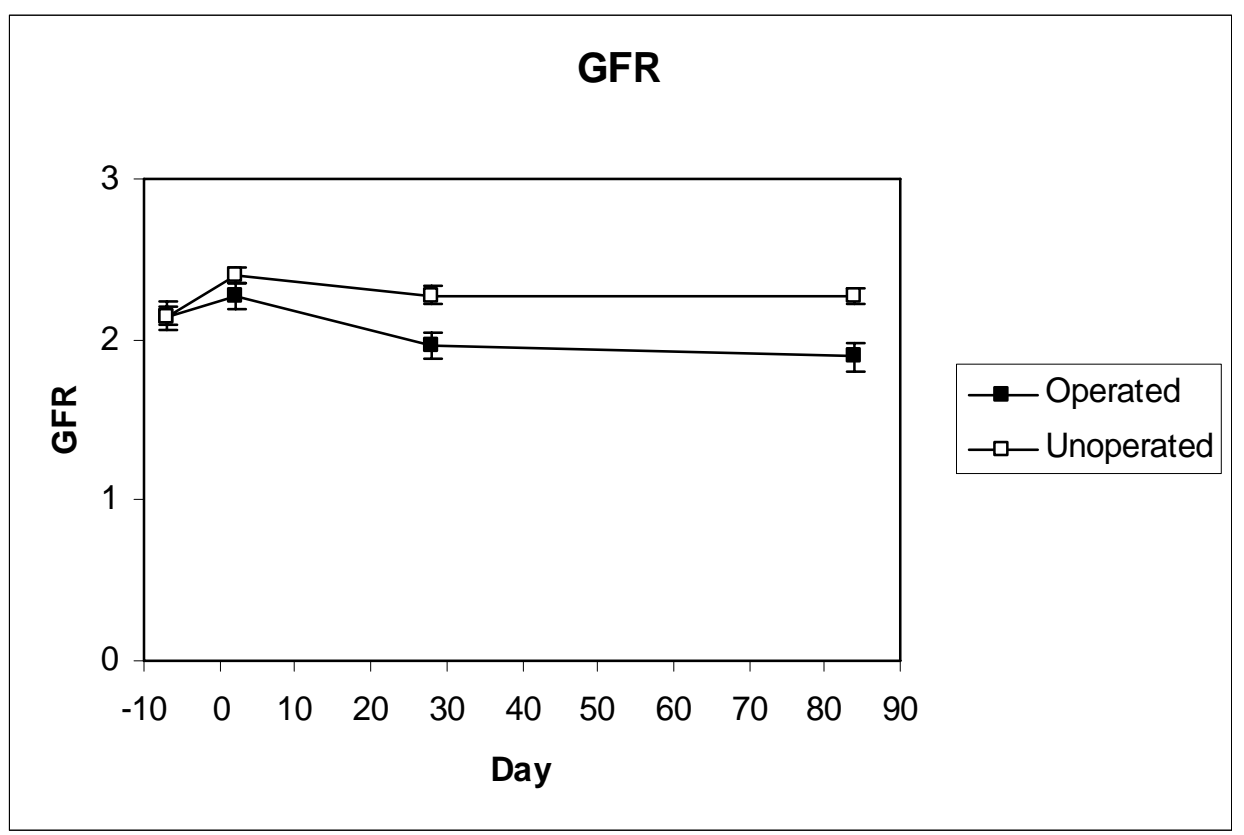


Figure 2: Comparison of mean longitudinal length between operated and un-operatedkidneys over time.

(Nephrotomy performed at Day=0)

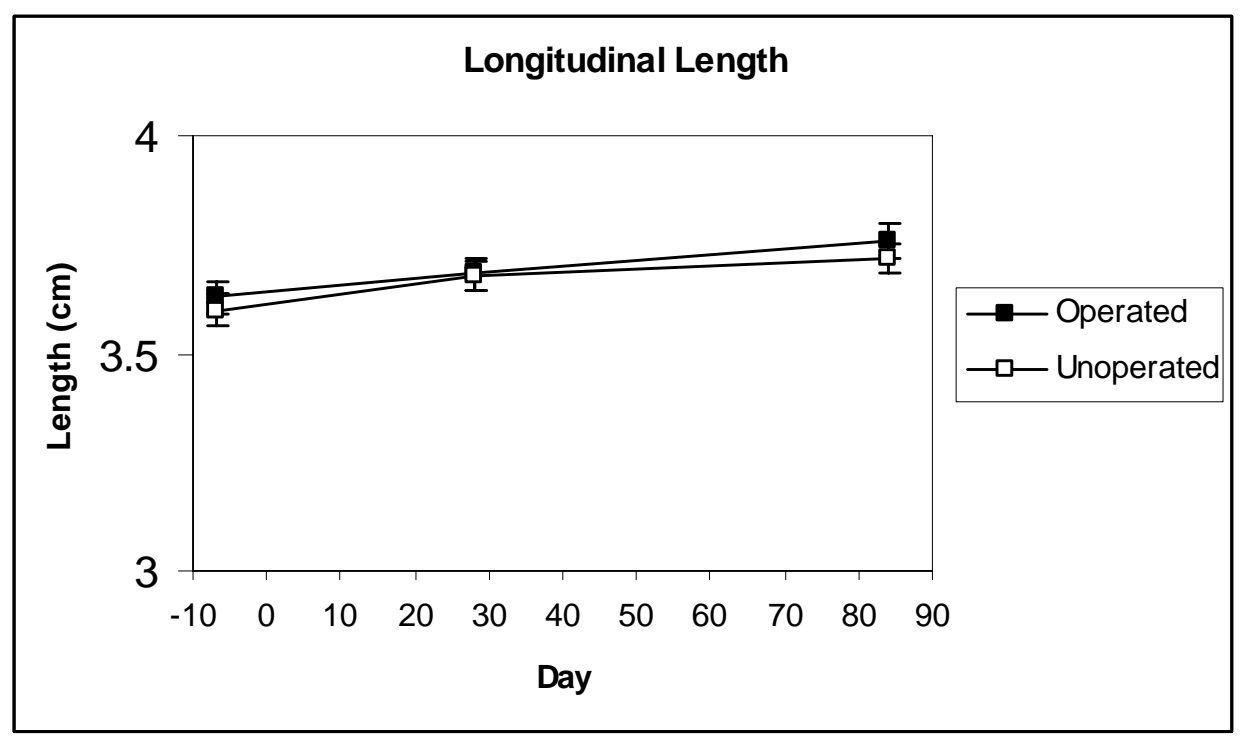


Figure 3: Comparison of mean longitudinal width between operated and un-operated kidneys over time.

(Nephrotomy performed at Day=0)

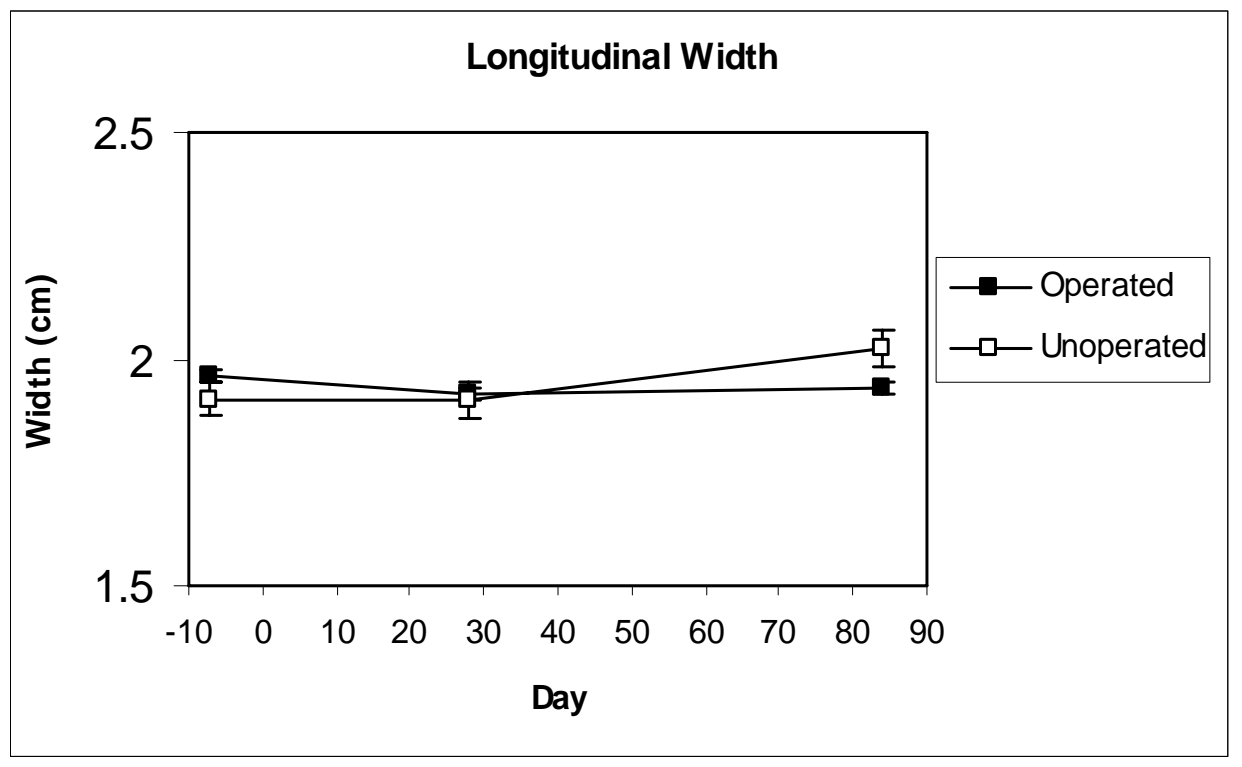


Figure 4: Comparison of mean transverse width between operated and un-operated kidneys over time.

(Nephrotomy performed at Day=0)

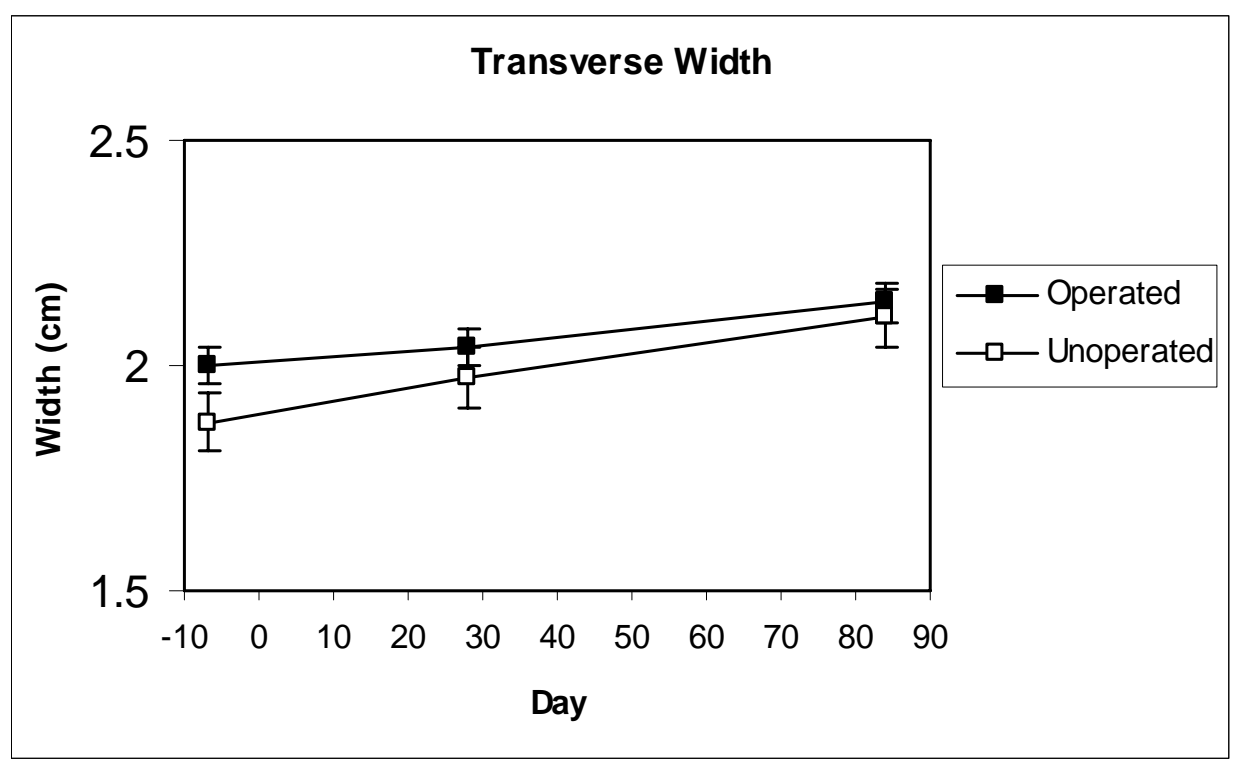


Figure 5: Comparison of mean transverse depth between operated and un-operated kidneys over time.

(Nephrotomy performed at Day=0)

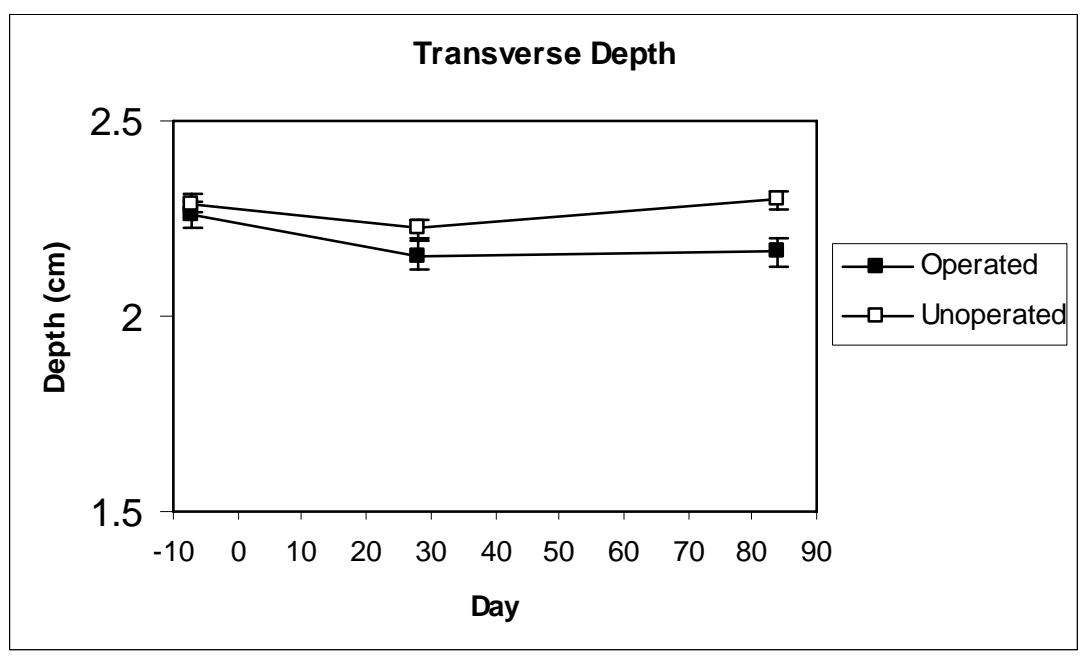


Figure 6: Comparison of mean longitudinal circumference between operated and un-operated kidneys over time.

(Nephrotomy performed at Day=0)

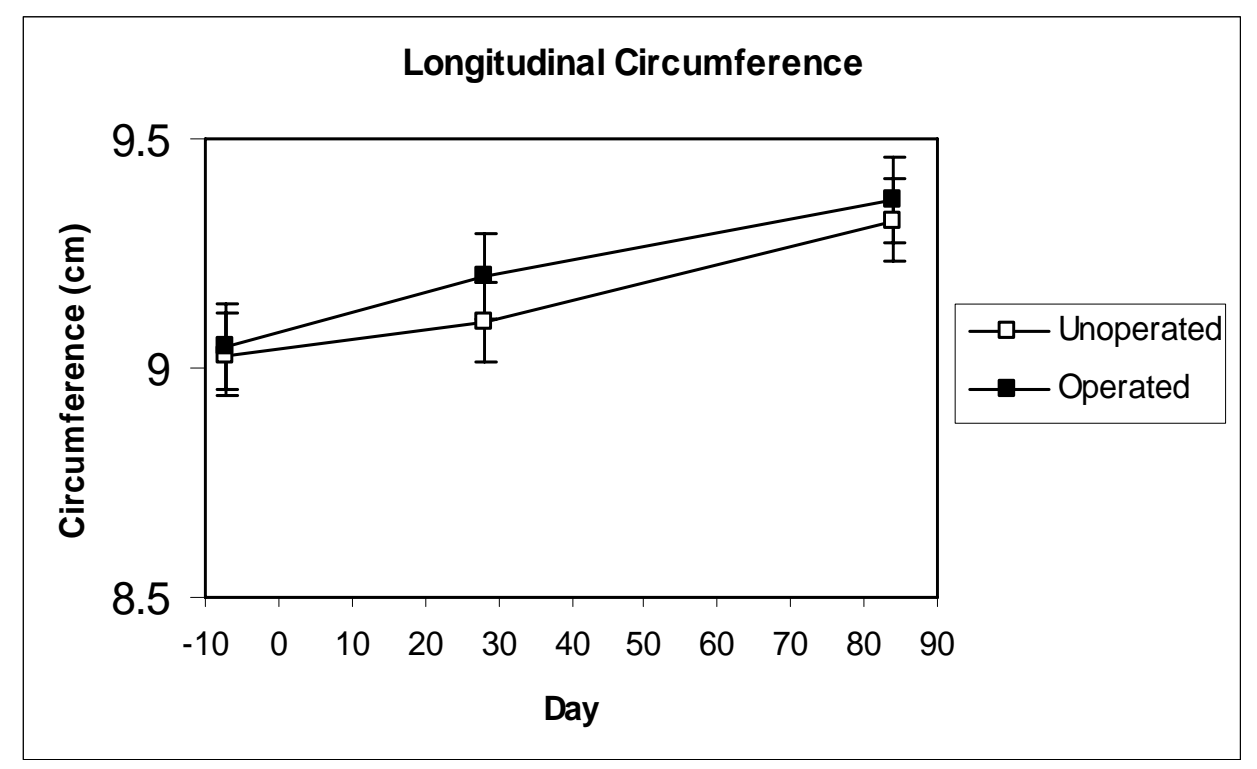


Figure 7: Comparison of mean longitudinal area between operated and un-operated kidneys over time.

(Nephrotomy performed at Day=0)

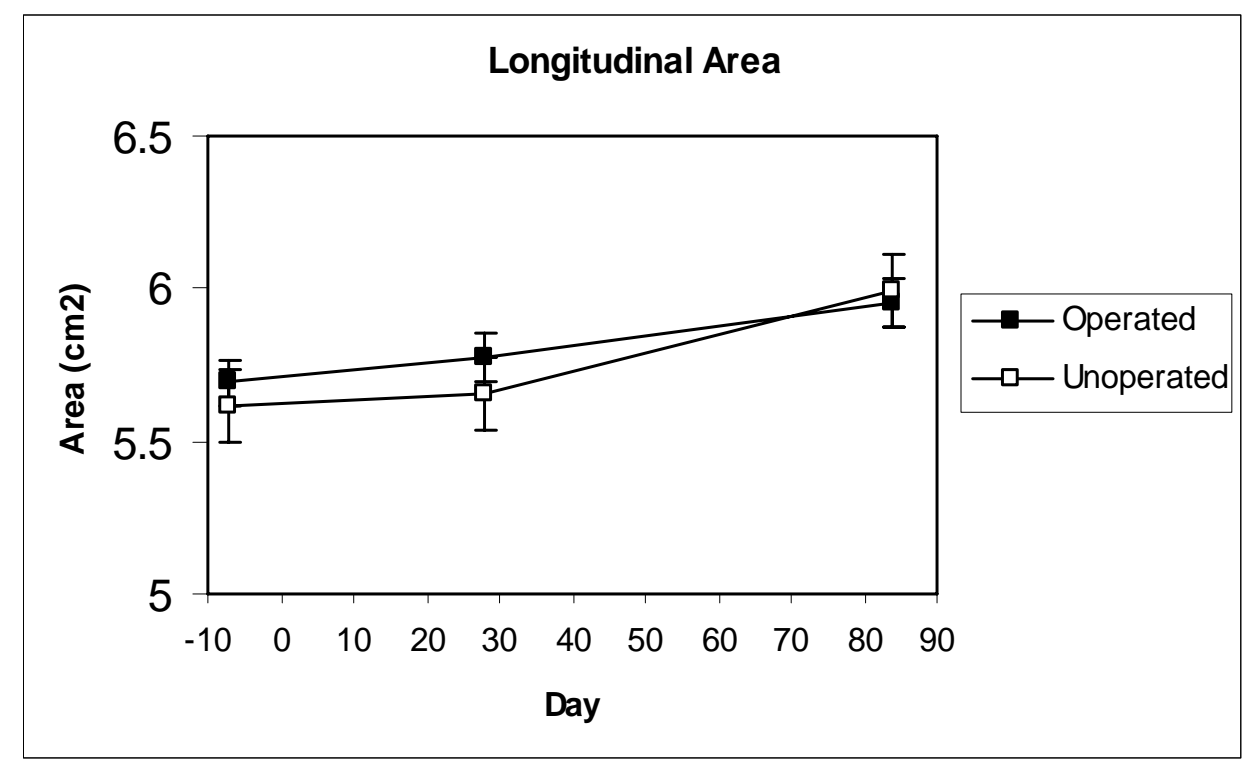


Figure 8: Comparison of mean transverse circumference between operated and un-operated kidneys over time.

(Nephrotomy performed at Day $=0$ )

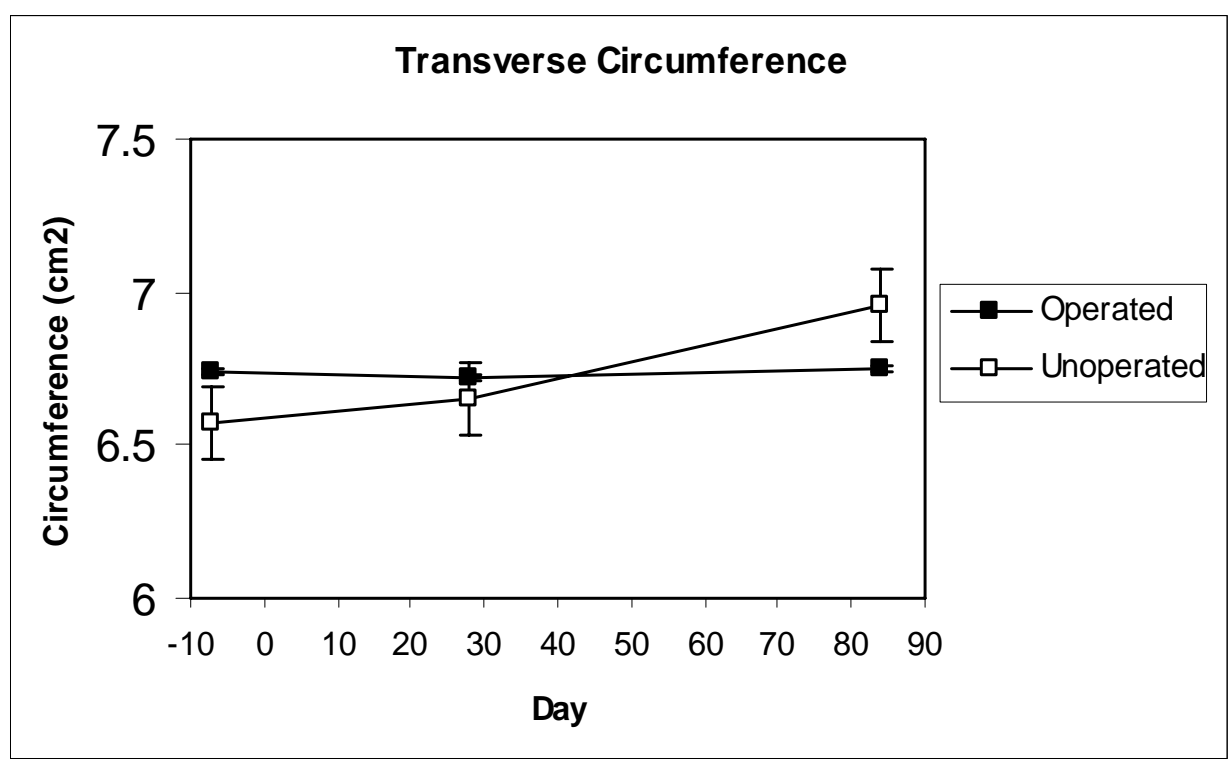


Figure 9: Comparison of mean transverse area between operated and un-operated kidneys over time.

(Nephrotomy performed at Day=0)

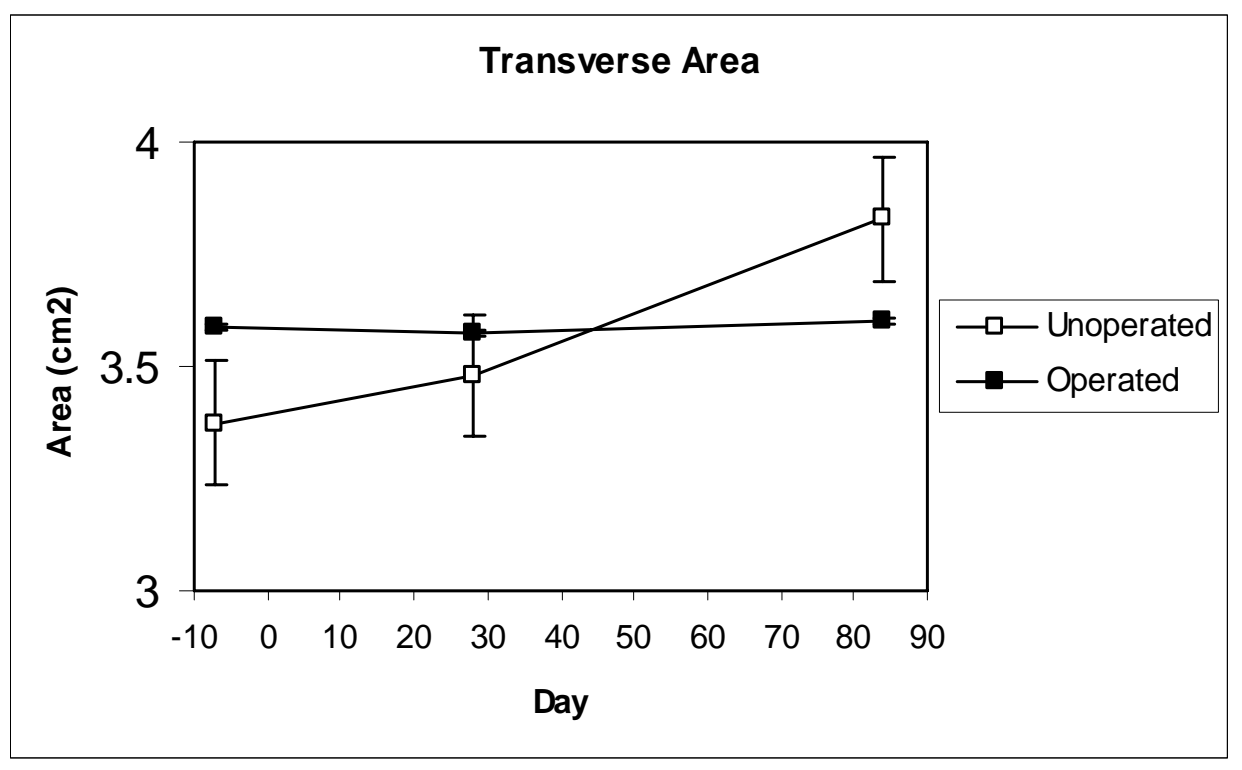




\section{VITA}

Michael King was born in London, England to New Zealand parents. He grew up in Auckland, New Zealand, and graduated from Massey University Veterinary School in December, 2000.

Michael completed an internship in small animal surgery at Franklin Veterinary Services Referral Center in Auckland New Zealand. He was then accepted into a rotating internship in small animal medicine and surgery at the Virginia-Maryland Regional College of Veterinary Medicine, beginning June, 2002. At the completion of that year he was accepted into a program of residency in small animal surgery at the VirginiaMaryland Regional College of Veterinary Medicine, pursuing the degree of Master of Science in Biomedical and Veterinary Sciences. 